RSC Adv., 2014,4, 11610-11623

DOI: 10.1039/C3RA46913A 


\title{
ESR Study of the Spin Adducts of three analogues of DEPMPO substituted at $\mathrm{C}_{4}$ or $\mathrm{C}_{3}$
}

\author{
Florence Chalier, ${ }^{a *}$ Jean-Louis Clément, ${ }^{a}$ Micaël Hardy, ${ }^{a}$ Paul Tordo, ${ }^{a}$ and Antal \\ Rockenbauer ${ }^{\text {b }}$
}

Received 00th November 2013, Accepted 00th January 2012

DOI: $10.1039 / x 0 \times x 00000 x$

www.rsc.org/

before proofs

\section{Introduction}

Nitrones have been used to trap various oxygen centred radicals. However, with the superoxide, $\mathrm{O}_{2}^{-\bullet}$, which is the

${ }^{a}$ Laboratoire SREP, Institut de Chimie Radicalaire - UMR 7273, CNRS and Aix-Marseille Univ. - case 521, Centre de Saint Jérôme, 13397 Marseille Cedex 20, France.

$b$ Research Centre for Natural Sciences, Institute for Molecular Pharmacology, H-1525 Budapest, PO Box 17, Hungary.

* To whom correspondence should be addressed. Dr F. Chalier, Phone 334912889 23; Fax 334912887 58; email: florence.chalier@amu.univ-mrs.fr primary upstream radical of the radical reaction chain of the oxidative stress ${ }^{1}$ and is induced in several physiological disorders, the nitrone adducts were generally too short-living. With the very popular nitrone DMPO, ${ }^{2}$ the half-life time of the superoxide adduct is inferior to $1 \mathrm{~min}$. The trapping of the hydroxyl radical, $\mathrm{HO}^{*}$, which is the predominant species contributing to cellular damages, afford adducts more persistent. Compared with DMPO, the phosphorylated nitrone DEPMPO $^{3}$ (Scheme 1) presents three major advantages. The first marked advantage is the higher persistency of its adducts with the oxygen centred radicals. For example the half-life of the superoxide adduct is 15 times higher than that of adduct 
DMPO-OOH and the alkylperoxyl radicals adduct can be observed in aqueous phase. ${ }^{4}$ The second advantage is that the decomposition of the superoxide adduct into another paramagnetic species since, the hydroxyl adduct was proved not to be spontaneous and can be avoided by using a superoxide concentration inferior or equal to $0.5 \mathrm{mM}$, as found in vivo. The third advantage is the additional information obtained from the phosphorus-coupling constant allowing an easier identification of the trapped radical structure. The ESR spectra of the superoxide adduct (DEPMPO-OOH) and of the peroxyl radical adducts (DEPMPO-OOR) have some characteristic shape signals and were attributed mainly to one diastereoisomer adduct obtained after the trans addition of the radicals versus the phosphoryl group, on the less hindered face of the pyrroline ring. However, each signal exhibited a dramatic alternating linewidth owing to a sufficiently slow chemical exchange between two sets of conformers of the diastereoisomer. This phenomenon may impede the accurate identification of the radicals trapped in vivo from spectra containing the superimposed signals of several adducts. As the ESR signal patterns of adducts formed is correlated to their geometries, we decided to simplify the spectra obtained through a geometry of the initial nitrones favouring stereoselective formation of adducts and their fast conformational exchange. Introduction of a phenyl group on the ring of DMPO trap induces a rigid conformation of this ring and is therefore beneficial for the superoxide radical trapping. ${ }^{5}$ Earlier studies showed that the pseudorotation occurring within the ring of stable $\beta$ phosphorylated pyrrolidinyloxyl radicals was slowed down by the ring substitution with a phenyl group. ${ }^{6}$ In the DEPMPO series, synthesis of the 3-phenyl ${ }^{7}$ and 4-phenyl ${ }^{8}$ and 4hydroxymethyl ${ }^{9}$ DEPMPO analogue named 3-PhDEPMPO, 4PhDEPMPO and 4-HMDEPMPO respectively (Scheme 1), were recently reported.

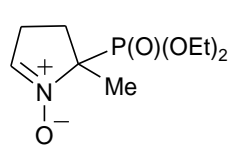

DEPMPO

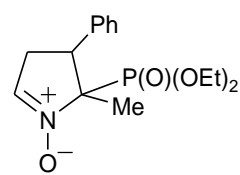

4-PhDEPMPO

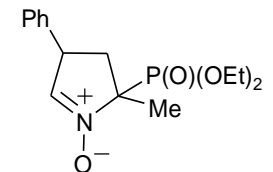

3-PhDEPMPO

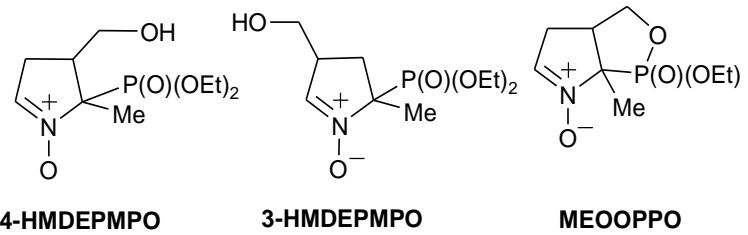

Scheme 1. Chemical structures of DEPMPO and new derivatives.

The presence of both kinds of substituents led to an important steric effect on the course of addition of the superoxide radical. In the presence of superoxide, the cis diastereoisomers of these three nitrones, where the phosphoryl group and the phenyl or hydroxymethyl substituent are in cis position, afforded stereoselectively trans adducts. Compared to DEPMPO-OOH, the superoxide trans adduct versus phosphorus on $\left(3 R^{*}, 5 R^{*}\right)$ 3-PhDEPMPO or (4R*, 5R*)-4-PhDEPMPO are respectively less persistent, or at least so persistent when the trans adduct with $\left(4 \mathrm{R}^{*}, 5 \mathrm{R}^{*}\right)-4$-HMDEPMPO is more persistent with a $25 \%$ longer half-life. Moreover, the signal of these adducts present also the alternating line-width phenomenon due to a slow chemical exchange between two conformer sets, with a rate constant on the same order than that of DEPMPO-OOH. The spin trapping behaviour of the diasteroisomeric forms of this nitrone are described thoroughly hereafter and compared to the spin trapping behaviour of two new substituted DEPMPO derivatives including a $\mathrm{C}_{3}$-substituted analogue (nitrone 3HMDEPMPO Scheme 1) and a bicyclical one named MEOOPPO (Scheme 1). We investigate relationship between the substitution of the pyrroline ring and the general patterns of the adduct signals.

\section{Results and discussion}

\section{Synthesis of Nitrones 3-HMDEPMPO and MEOOPPO.}

The nitrone 3-HMDEPMPO (5-diethoxyphosphoryl-5-methyl3-hydroxymethyl-1-pyrroline $\mathrm{N}$-oxide) substituted at $\mathrm{C}_{3}$ was prepared in a two-step synthesis from 4-hydroxymethyl-2methyl-1-pyrroline $\underline{4}$ that could be issued from an eight-step synthesis ${ }^{10}$ or from the four-step synthesis given in Scheme 2. It was obtained by cyclisation of an adequate $\gamma$-aminoketone.
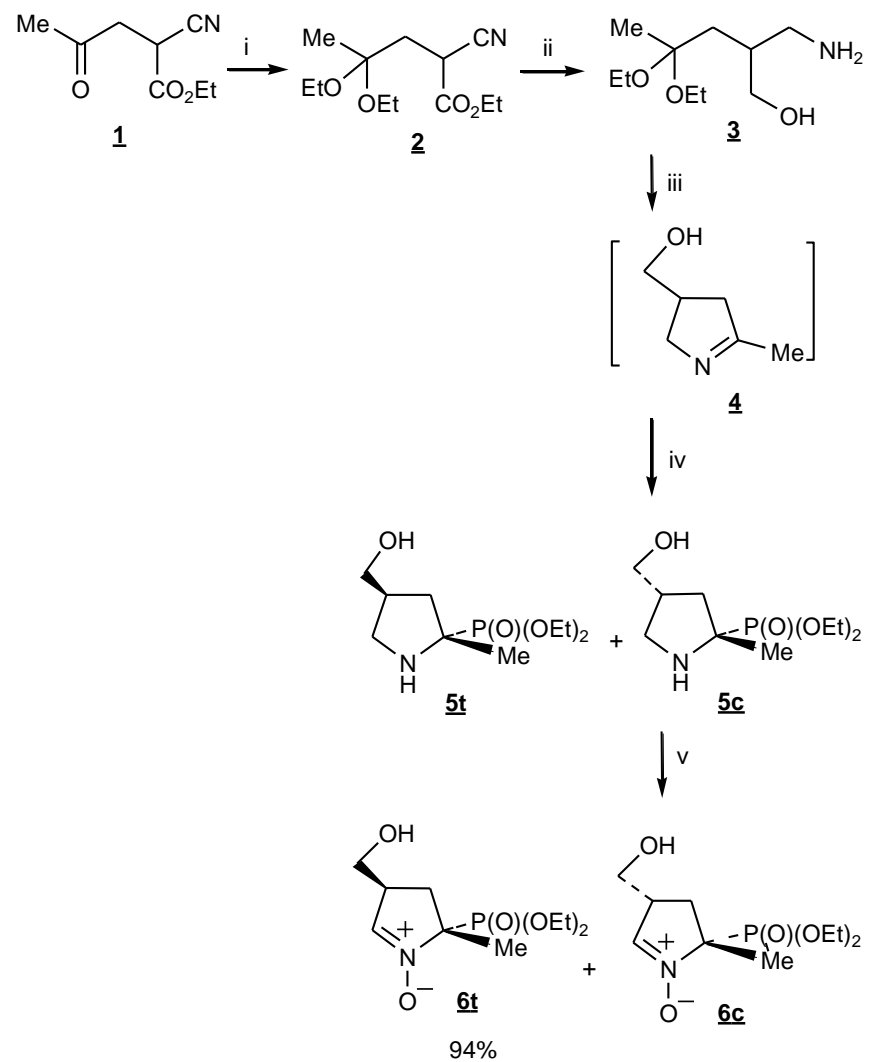

Scheme 2. Synthesis of nitrone 3HMDEPMPO. Reagents and conditions: (i) $\mathrm{HC}(\mathrm{OEt})_{3}$, resin Amberlyst 15, $\mathrm{CH}_{2} \mathrm{Cl}_{2}, 0-5{ }^{\circ} \mathrm{C}$, 99\%; (ii) $\mathrm{LiAlH}_{4}, \mathrm{THF}, 3 \mathrm{~h}$ at $25{ }^{\circ} \mathrm{C}$, then $1 \mathrm{~h}$ at $57{ }^{\circ} \mathrm{C}, 36 \%$; (iii) 1) $\mathrm{HCl} \mathrm{THF} / \mathrm{H}_{2} \mathrm{O}(5: 1)$, rt, 2) $\mathrm{K}_{2} \mathrm{CO}_{3}$ $\mathrm{THF} / \mathrm{H}_{2} \mathrm{O}$ (5:1), rt; (iv) $\mathrm{HPO}(\mathrm{OEt})_{2}, \mathrm{rt}, 40 \%$; (v) $\mathrm{H}_{2} \mathrm{O}_{2}, \mathrm{Na}_{2} \mathrm{WO}_{4}, \mathrm{CH}_{3} \mathrm{OH} / \mathrm{H}_{2} \mathrm{O}$ $(2: 1), 4{ }^{\circ} \mathrm{C}, 32 \%$. 
Synthesis of ethyl 2-cyano-4-diethoxypentanoate $\underline{\mathbf{2}}$ is described, ${ }^{11}$ but we obtained $\underline{\boldsymbol{2}}$ via the quantitative transacetalisation of ethyl 2-cyano-4-oxopentanoate $\underline{\mathbf{1}}$, which was synthesized from chloroacetone and ethyl cyanoethanoate. ${ }^{12}$ The yield (36\% not optimized) of the reduction step of the cyano and ester functions of $\underline{\boldsymbol{2}}$ using $\mathrm{LiAlH}_{4}$ was lowered by formation of by-products such as some conjugated oxoenamines. The amino function of 2aminomethyl-4-diethoxypentan-1-ol $\underline{\mathbf{3}}$ was let to react with the carbonyl function delivered by $\mathrm{HCl}$ to afford the expected 4hydroxymethyl-1-methyl-2-pyrroline $\underline{4}$. This pyrroline was not isolated and was let crude to react with diethylphosphite. The ensuing phosphorylated pyrrolidine $\underline{\mathbf{5}}$ was obtained in $40 \%$ yield with an $94 \%$ excess of the $\left(3 R^{*}, 5 R^{*}\right)$ diastereoisomer $(\underline{\mathbf{5}} \mathrm{t})$ where the hydroxymethyl substituent and the phosphoryl group are in trans position. This pyrrolidine was easily oxidized to nitrone $\underline{\mathbf{6}}$ (Scheme 2), under mild conditions using the system $\left(\mathrm{H}_{2} \mathrm{O}_{2}\right.$-sodium tungstate) in aqueous methanol. The two diastereoisomers of nitrone 3-HMDEPMPO $\underline{\mathbf{6}}$ were not separated. However, the isomer mixture contained mainly $(94 \%)$ the $\left(3 R^{*}, 5 R^{*}\right)$ diastereoisomer $(\underline{\mathbf{6}} \mathbf{t})$.

The bicyclical nitrone (ㅁ) called MEOOPPO was actually obtained in $45 \%$ yield from the $\left(4 \mathrm{R}^{*}, 5 \mathrm{R}^{*}\right)$ diastereoisomer of nitrone $4 \mathrm{HMDEPMPO}^{9}$ (named hereafter $\underline{\mathbf{7 c}}$ ) where the phosphoryl group and the hydroxymethyl substituent are in cis position (Scheme 3). The purification of $\underline{\mathbf{8}}$ was not straightforward and needed a dry atmosphere because $\underline{\mathbf{8}}$ was easily hydrolyzed. This nitrone was degraded in a few weeks in spite of its storage in an inert atmosphere at $-18^{\circ} \mathrm{C}$.

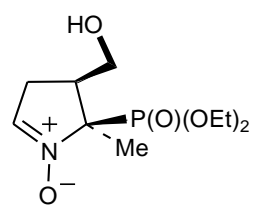

$\underline{7 c}$

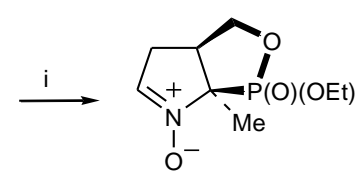

$\underline{8}$
Scheme 3. Synthesis of nitrone MEOOPPO. Reagents and conditions: (i) NaH, DME, $r t, 45 \%$.

\section{ESR Studies.}

In the present work, the spin trapping capacities of the nitrones were tested in aqueous phase mainly toward superoxide and the hydroxyl radical, two oxygen centred radical species that are of the largest biological relevance. Trapping of several carbon centred species was also tested in aqueous buffer and trapping of a bulky peroxyl radical was investigated in organic phase. When ESR signal increased in the first minutes of experiments the spectra recorded and given hereafter corresponded to the largest signals. Assignment of the signals was done through their simulation (gray coloured lines in the figures of the spectra) using the ESR software ROKI developed in the Central Research Institute of Chemistry, Hungary. ${ }^{13}$ Four types of hyperfine coupling constant $\mathrm{a}_{\mathrm{H} \gamma}$ ( 3 various constants for the $\mathrm{H}$ of the ring and one for the $3 \mathrm{H}$ of the methyl substituent), were sometime used in simulation for a better fit even when no superhyperfine structure of the pattern was seen. The two diasteromeric forms, (4R*, 5R*)-4-HMDEPMPO $(\underline{\mathbf{7 c}})$ and $\left(4 \mathrm{~S}^{*}, 5 \mathrm{R} *\right)$-4-HMDEPMPO (ㅍt), led to adducts with different spectra and different coupling features. Therefore, they were distinctively studied. The calculated values of the coupling constants are given in Table 1 for the diastereoisomer $\underline{\mathbf{7 c}}$, and in Table 3 for the other diastereoisomer $\left(4 R^{*}, 5 R^{*}\right)$ diastereoisomer of nitrone 4HMDEPMPO ${ }^{9} \underline{\mathbf{7 t}}$ and for the cyclical nitrone MEOOPPO $\underline{\mathbf{8}}$, and in Table 4 for nitrone 3 HMDEPMPO ‥ Because of the preponderance of the trans diastereoisomer (ㅎt) in the nitrone 3-HMDEPMPO samples, the major signals observed in the spin trapping experiments were assigned to the $\underline{\mathbf{6}} \mathbf{t}$ adducts.

a) Spin Trapping of Superoxide: superoxide was generated in phosphate buffer at $\mathrm{pH} 7.3$ containing DETAPAC (diethylenetriaminepentaacetic acid) using two systems such as the well-known [xanthine oxidase / oxygen / hypoxanthine system $]\left(\left[\mathrm{XO} / \mathrm{O}_{2} / \mathrm{HX}\right]\right.$ system $)$ or as the $\left[\mathrm{KO}_{2} /\right.$ crown ether /DMSO] system. Unambiguous assignment of the signals obtained in the presence of the nitrones to the superoxide adducts was supported by their similarity when using both generating systems and by their complete inhibition when superoxide dismutase (SOD) was added in the $\left[\mathrm{XO} / \mathrm{O}_{2} / \mathrm{HX}\right]$ mixture. The spectra observed in the presence of superoxide were given in Figure 1. Each spectrum of superoxide trapping showed an alternate line-width phenomenon which was attributed, like for DEPMPO-OOH, to a slow exchange between two conformers sets for each diastereoisomer adducts when the two are present. The simulation of the signals was

(a)
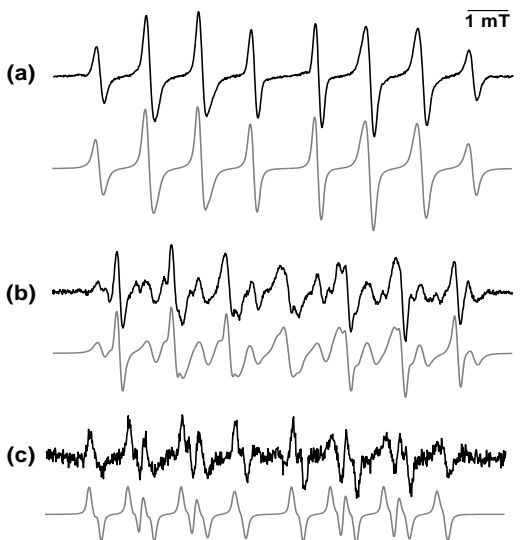

(d)

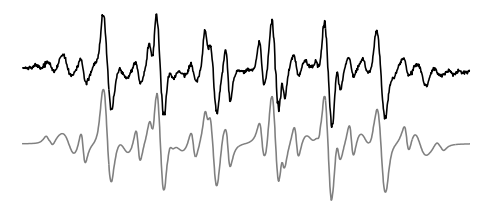

Figure 1. Spin trapping of superoxide with nitrones $\underline{7}$ or $\underline{8}$ or $\underline{6}$. Spectra obtained (dark lines) and computer simulated (gray lines) from a mixture containing HX $(0.4 \mathrm{mM})$, XO $\left(0.04 \mathrm{U} \mathrm{mL}^{-1}\right)$, DETAPAC $(1 \mathrm{mM})$ in phosphate buffer $(0.1 \mathrm{M}, \mathrm{pH} 7.3)$ in the presence of (a) $\mathbf{7 c}(61 \mathrm{mM})$ after 9 min incubation and argon bubbling (1 min); (b) $\underline{7 t}(50 \mathrm{mM})$ after $7 \mathrm{~min}$ incubation; (c) $\underline{\mathbf{8}}$ (50 $\mathrm{mM})$ after $3 \mathrm{~min}$ incubation and 3 scans; (d) $\underline{\mathbf{6}}$ (50 mM) after 7 min incubation. Spectrometers settings: microwave power $10 \mathrm{~mW}$; modulation amplitude, $0.702(a-b), 0.497(c), 0.787(d), 1$ (h); time constant, $0.128 \mathrm{~s}$; gain $10^{5}$; sweep time, $83.89 \mathrm{~s}(\mathrm{a}-\mathrm{c}), 335,54 \mathrm{~s}(\mathrm{~d})$; conversion time, 82 $m s(a-c), 327.68 m s(d)$. 
done assuming that only the $\mathrm{H}_{\beta}$ and ${ }^{31} \mathrm{P}$ couplings differed significantly in the two conformer sets while the $\mathrm{g}$ factor, the ${ }^{14} \mathrm{~N}$ couplings and the hydrogen $\gamma$-hfcs were very close. The relaxation contribution in the hyperfine lines was also considered the same for the two sets. For DEPMPO-OOH, four simulation solutions for the two conformation sets could be found at ambient temperature conditions. ${ }^{14}$ These solutions differed by the $\mathrm{H}_{\beta}$ and ${ }^{31} \mathrm{P}$ coupling values and the populations $\mathrm{p}_{1}$ et $\mathrm{p}_{2}$ of the minor and major conformer set. The coupling values averaged on the two sets $\left(\langle A\rangle=p_{1} A_{1}+p_{2} A_{2}\right)$ are the same for all the solutions. These average values induce the lines positions of the signal observed and explain the line width alternation. Decreasing the exchange rate in a lowertemperature domain allowed discriminating the best solution that was the two conformer sets with the largest Ap difference, and the preponderant set had the highest $A_{P}$ values.

We already reported ${ }^{9}$ the ESR parameters of the superoxide adduct with the cis diastereoisomer $4-\mathrm{HM}_{\text {cis }}$ DEPMPO (두) at the outcome of experiments using the $\left[\mathrm{KO}_{2} /\right.$ crown ether] system or $\left(\left[\mathrm{XO} / \mathrm{O}_{2} / \mathrm{HX}\right]\right.$ as generating system. The $\underline{\mathbf{7 c}}-\mathrm{OOH}$ signal (given in Fig 1a) quite asymmetric was observed alone in the first minutes of experiments (more than $10 \mathrm{~min}$ of incubation with $\left[\mathrm{XO} / \mathrm{O}_{2} / \mathrm{HX}\right]$ system) has be shown to be due to only one diastereoisomer form (the trans adduct $\underline{7 c}-\mathrm{OOH}_{\mathrm{t}}$ versus phosphorus group) of the superoxide adduct in two conformers sets in a relative slow chemical exchange although one was preponderant. We give again herein theses ESR parameters in Table 1 , as well as a second simulation solution to the observed spectrum given in Figure 1a. The second simulation solution presented an equal regression coefficient for a higher $A_{p}$ difference for the two sets and a higher difference also in their populations. However, the first solution dominated (with the best regression coefficient), in simulation of a series of spectra scanned when the exchange rate between the conformer sets was slowing down by increasing the solvent viscosity. ${ }^{9}$ As it was demonstrated by Pople and Cremer, ${ }^{15}$ the

Table 1 ESR parameters of several radical adducts with 4-HMcisDEPMPO mainly at 298K

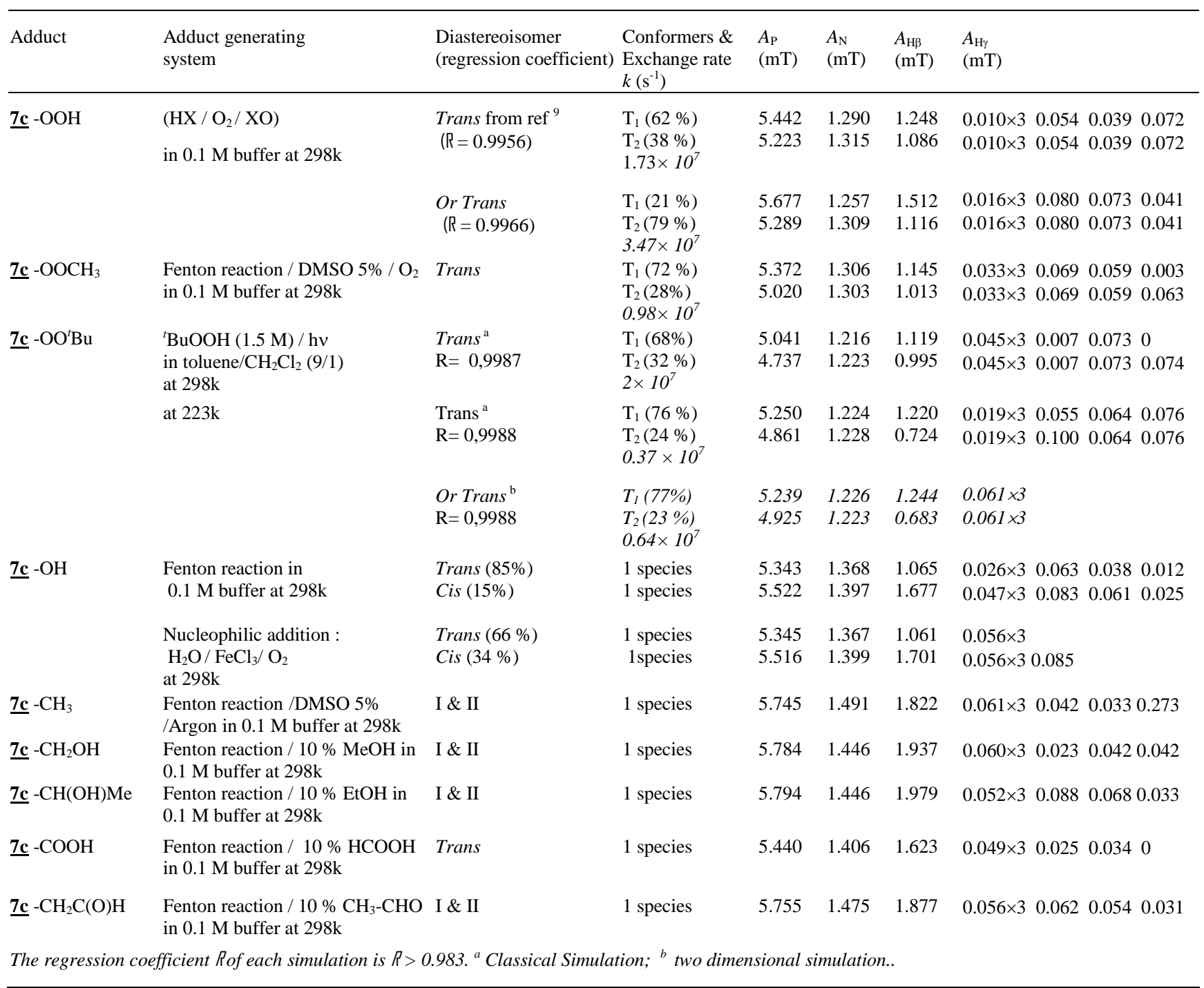




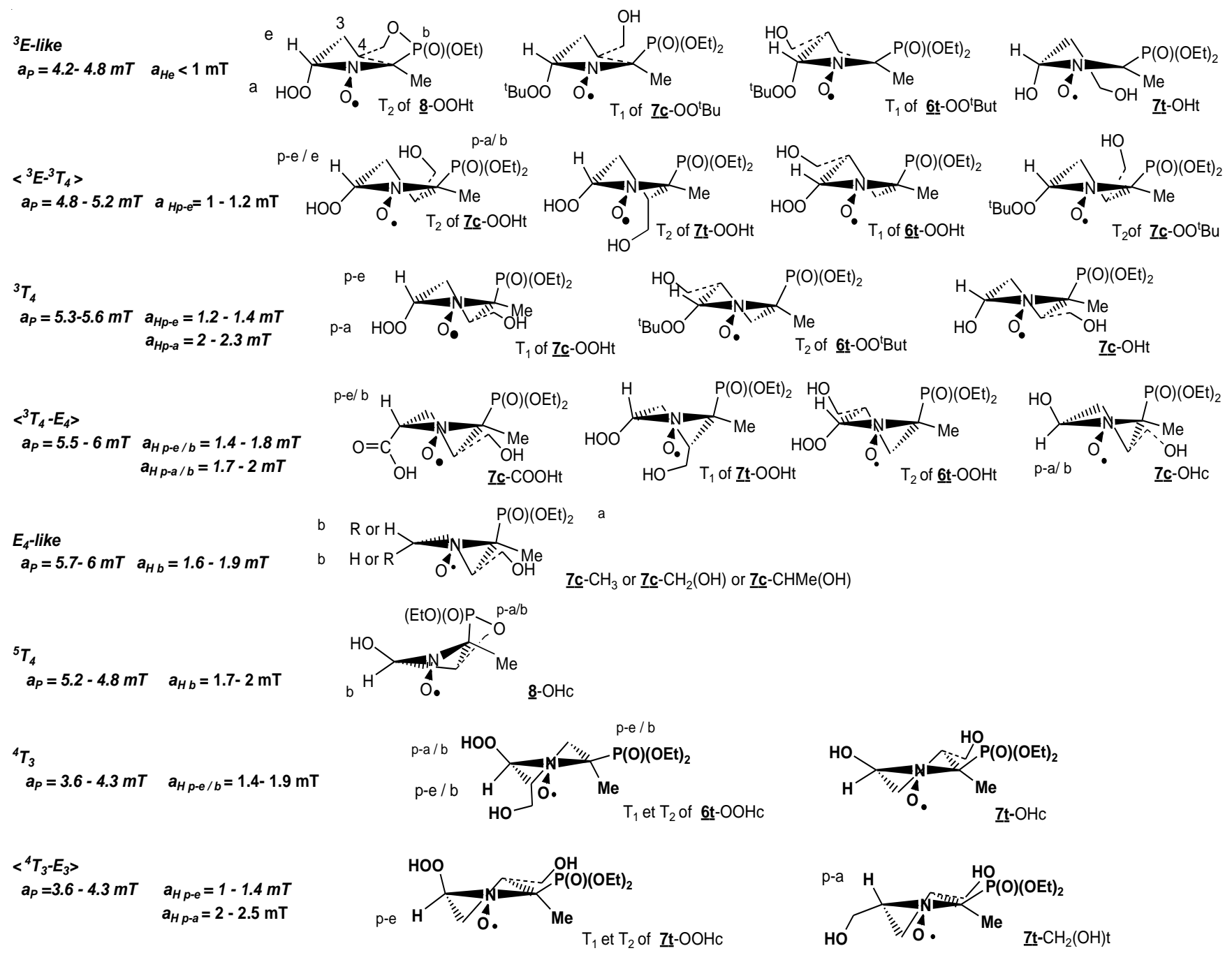

Scheme 4 Average geometries of the 5R nitrone adducts in phosphate buffer.

intrinsic flexibility of the 5-membered nitroxide ring can be characterized by the amplitude and phase of the ring deformation. Because of the dihedral rules followed by the $\beta$-coupling of the electron of the nitroxide, (see table 2 calculated for DEPMPO-OOH ${ }^{16}$ ) the major set, in this first simulation solution of the $\underline{\mathbf{7 c}}-\mathrm{OOH}_{t}$ signal, has the $\mathrm{A}_{\mathrm{p}}$ and $\mathrm{A}_{\mathrm{H}}$ values characteristic for pseudo-axial phosphoryl group and pseudo-equatorial $\mathrm{H}$ of a twist envelope $\left({ }^{3} \mathrm{~T}_{4}\right.$ for $2 \mathrm{R}, 4 \mathrm{~S}, 5 \mathrm{R}-$ nitroxyde or ${ }^{4} \mathrm{~T}_{3}$ for $2 \mathrm{~S}, 4 \mathrm{R}, 5 \mathrm{R}$-nitroxyde). Therefore the $\mathrm{OOH}$ group is also pseudo-axial and the hydromethyl group is

Table 2 Relation between the geometry of the substituent $\mathrm{P}$ or $\mathrm{H}_{\beta}$ and their coupling constants for DEPMPO adducts ${ }^{16}$

\begin{tabular}{lccc}
\hline $\mathrm{X}\left(\mathrm{H}_{\beta}\right.$ or $\left.\mathrm{P}\right)$ position & $\begin{array}{c}\mathrm{XCNPz} \\
\text { Dihedral angle }\left(^{\circ}\right)\end{array}$ & $\begin{array}{c}A_{\mathrm{P}} \\
(\mathrm{mT})\end{array}$ & $\begin{array}{c}A_{\mathrm{H} \beta} \\
(\mathrm{mT})\end{array}$ \\
\hline axial & 6.5 & 5.93 & 2.57 \\
pseudo-axial & 17.6 & 5.45 & 2.36 \\
Bisectional & 30 & 4.5 & 1.95 \\
pseudo-equatorial & 42.4 & 3.27 & 1.41 \\
equatorial & 53.5 & 2.12 & 0.92 \\
\hline
\end{tabular}

equatorial. The minor set adopts an average geometry with distortion of the twist ring, that is traduced by a C-P bond less axial (lower $A_{p}$ value) and a more axial $O O H$ group (lower $A_{H}$ value). This geometry is named, $\left\langle{ }^{3} \mathrm{E}^{3} \mathrm{~T}_{4}\right\rangle{ }^{17}$ for the $2 \mathrm{R}, 4 \mathrm{~S}, 5 \mathrm{R}-$ adduct $\mathbf{7 c}-\mathrm{OOH}_{\mathrm{t}}$ (see Scheme 4). In the second simulation solution (with a higher $A_{p}$ difference for the two sets), the preponderant conformer, with the smallest Ap and aH values, adopts the previously invoked distorted twist geometry towards one envelope geometry $\left(\left\langle{ }^{3} \mathrm{E}^{-}{ }^{3} \mathrm{~T}_{4}\right\rangle\right.$ for the $2 \mathrm{R}, 4 \mathrm{~S}, 5 \mathrm{R}$-adduct $\mathbf{7 c}$ OOHt; see Scheme 4), when the geometry of the minor conformer is distorted from the twist to the other envelope

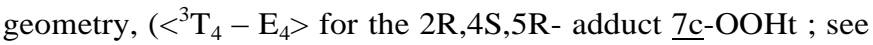
Scheme 4). Therefore, in this second simulation solution, one of the groups, either $\mathrm{OOH}$ group or the phosphorus one, is less axial when the other is more. Nevertheless, the pseudo-axial positions of the $\mathrm{C}-\mathrm{P}$ bond or $\mathrm{C}-\mathrm{OOH}$ bond do not minimize the steric interactions, however, these positions stabilize the adduct by anomeric interactions, ${ }^{7,18}$ because of a strong hyperconjugative interaction of the orbitales $\sigma^{*}$ of the $\mathrm{C}-\mathrm{P}$ bond or $\sigma^{*}$ of the $\mathrm{C} 2-\mathrm{O}$ bond with the $\pi$ or the $\pi *$ of the $\mathrm{N}$ O•. Both solutions show a higher average value for Ap of $\underline{7 c}-$ OOHt than that of DEPMPO-OOHt therefore a more axial 
position of the phosphorus group inducing a higher anomeric stabilizing effect of the $\mathrm{CP}$ bond on the $\mathrm{NO}^{-}$moiety. This stabilizing interaction explains in part the higher persistency of

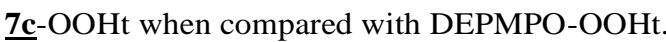

From recent theoretic QM/MM/MD calculations, the noticeable asymmetry of the signal of the DMPO-OOH adduct is proved also to result from a slow chemical exchange between two conformation "families" (or "sites", or "sets"), with a different dihedral angle $\angle \mathrm{OOCN}$ and separated by a $7 \mathrm{Kcal} / \mathrm{mol}-1$ energy barrier. ${ }^{19}$ In one family, the $\mathrm{OOH}$ group $(\angle \mathrm{OOC} 2 \mathrm{~N}=$ $80^{\circ}$ ) is above the ring main plane, while in the other family, the $\mathrm{OOH}$ group is oriented in the periphery of the ring $(\angle \mathrm{OOC} 2 \mathrm{~N}$ of $\left.300^{\circ}\right)$. In each family, a fast interconversion occurs between ${ }^{3} \mathrm{~T}_{4}$-like $\left(\mathrm{H}_{\beta}\right.$ pseudo-equatorial $)$ and ${ }^{4} \mathrm{~T}_{3}$-like $\left(\mathrm{H}_{\beta}\right.$ pseudo-axial $)$ conformations of the ring. The hfsc coupling constants $\mathrm{A}_{\mathrm{N}}$ and $\mathrm{A}_{\mathrm{H} \beta}$ showed that these two twist geometries are in equivalent populations. Theoretic QM/MM/MD calculations prove also that the rotation around the $\mathrm{C}_{2}-\mathrm{O}$ bond in DMPO-OH adduct does not induce a conformational slow exchange, ${ }^{20}$ as it can be supposed for DMPO-OOH.

For $\mathbf{7 c}-\mathrm{OOHt}$, we can consider that, as for DMPO, the rotations around the $\mathrm{O}-\mathrm{O}$ bond, and around the $\mathrm{C}_{2}-\mathrm{O}$ bond, contribute to the slow conformational exchange. Furthermore, the presence of the crowding substituents on the aminoxyl ring such as the hydroxymethyl and phosphorus groups can increase the energy barrier between the two conformations ${ }^{3} \mathrm{~T}_{4}$ or ${ }^{4} \mathrm{~T}_{3}$, and therefore, limits the ${ }^{3} \mathrm{~T}_{4} /{ }^{4} \mathrm{~T}_{3}$ equilibrium. This steric effect can explain an average geometry close to ${ }^{3} \mathrm{~T}_{4}$ for the $2 \mathrm{R}, 4 \mathrm{~S}, 5 \mathrm{R}-$ adduct and close to ${ }^{4} \mathrm{~T}_{3}$ for the other enantiomer.

In the rest of the text, for the signals obtained with $\underline{7 t}, \underline{\mathbf{6}}$ and $\underline{\mathbf{8}}$ nitrones, we report the solutions of simulation with the highest regression coefficients. From several solutions of simulation, with similar regression coefficients, we selected arbitrarily those with the smallest difference between populations of the conformer sets in chemical exchange. The equality of the populations was also an initial hypothesis to begin the simulation.

The trapping of superoxide with the other diastereoisomer, $\left(4 \mathrm{R}^{*}, 5 \mathrm{R}^{*}\right), \quad 4-\mathrm{HM}_{\text {trans }} \mathrm{DEPMPO}(\underline{\mathbf{7 t}})$ where the phosphoryl group and the hydroxymethyl substituent are in trans position led to more complicated spectra (fig 1b) owing the formation of two diastereoisomer adducts, but also of some minor nitroxides (around 10\%), that could be issued from decomposition of the superoxide adducts. The major signal of the $\underline{\mathbf{7 t}}-\mathrm{OOH}$ spectra, (fig 1b) exhibited a dramatically alternating linewidth (varying from $0.1 \mathrm{mT}$ up to $0.5 \mathrm{mT}$ ) with a phosphorus coupling constant smaller than that of the minor signal (see Table 3). Therefore, this signal was simulated with an exchange model of two sets of conformers (with a low exchange rate) and, was attributed to the superoxide adduct $\underline{\mathbf{7 t}}-\mathrm{OOHc}$, resulting on the cis-addition on the $\underline{\mathbf{7 t}}$ ring face of the phosphoryl group. Both

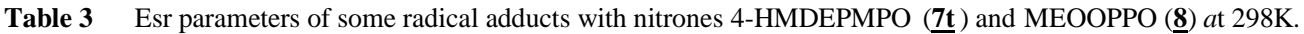

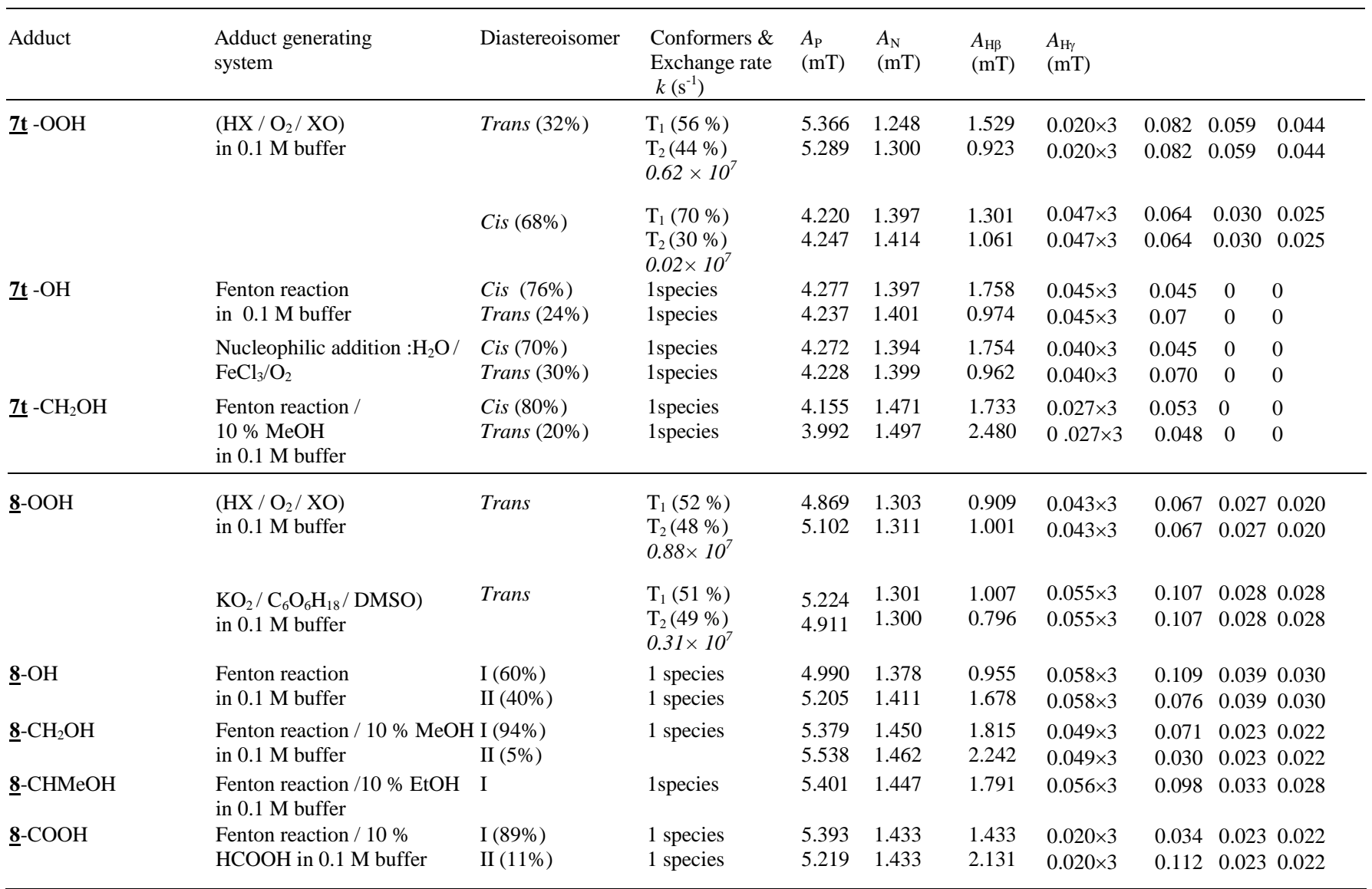


conformer sets of $\underline{\mathbf{7 t}}-\mathrm{OOHc}$, adopt an average geometry distorted from the twist geometry where the phosphorus group is nearly bisectional for hydroxylmethyl groups pseudoequatorial, and for $\mathrm{C}_{2}-\mathrm{H}$ bond nearly equatorial and therefore, $\mathrm{C}_{2}-\mathrm{OOH}$ bond pseudo-axial, $\left({ }^{4} \mathrm{~T}_{3}-\mathrm{E}_{3}\right\rangle$ geometry for the 2S,4R,5R-adduct 7t-OOHc; see Scheme 4). A minor signal with a higher phosphorus coupling constant was assigned to the trans superoxide adduct $\underline{\mathbf{7 t}}-\mathrm{OOH}$. This second signal was also simulated with an exchange model of two conformer sets which adopt an average geometry distorted from the twist geometry because the phosphorus can be more ou less pseudo-axial when the hydroxylmethyl group is axial and $\mathrm{C}_{2}-\mathrm{H}$ bond can be equatorial or bisectional $\left({ }^{3} \mathrm{E}_{-}{ }^{3} \mathrm{~T}_{4}\right\rangle$ and $\left\langle{ }^{3} \mathrm{~T}_{4}-\mathrm{E}_{4}\right\rangle$ geometry for the two conformers sets of $2 \mathrm{R}, 4 \mathrm{R}, 5 \mathrm{R}$ - adduct $\underline{\mathbf{7 t}}-\mathrm{OOHt}$; see Scheme 4). The positions (pseudo-axial) of the three crowded substituents explain the small ratio of this trans adduct. The conformer exchange rate for $\underline{\mathbf{7 t}}-\mathrm{OOH}_{\mathrm{c}}$ or for $\underline{\mathbf{7 t}}-\mathrm{OOH}_{\mathrm{t}}$ presented a lower value than that of $\underline{\mathbf{7 c}}-\mathrm{OOH}_{t}$, traducing an enhanced energy barrier between the conformer set. The slowing down of the exchange rate of the $\underline{\mathbf{7 t}-\mathrm{OOH}_{\mathrm{t}}}$ conformers in comparison with that of $\underline{\mathbf{7 c}}-\mathrm{OOH}_{\mathrm{t}}$, in same ratio, can be explained by vicinity of the hydroxymethyl group towards the hydroperoxyle group that could reduce the $\mathrm{OOH}$ free motion around the $\mathrm{C}_{2}-\mathrm{O}$ bond or the $\mathrm{O}-\mathrm{O}$ bond. In the case of the $\underline{\mathbf{7}}-\mathrm{OOH}_{\mathrm{c}}$ conformers, the motion of the $\mathrm{OOH}$ group can be altered by the steric hindrance of the phosphoryl group.

The bicyclic nitrone MEOOPPO (으) was expected to afford only the trans superoxide adduct because of the rigid geometry of its pyrroline ring and because one of its faces was overcrowded. The signal observed when using the $\left(\left[\mathrm{XO} / \mathrm{O}_{2} /\right.\right.$ $\mathrm{HX}$ ] generating system was not intense and not persistent; three scans were necessary to obtain a signal (fig 1c) that could be analyse although its fast vanishing. The spectrum of Fig. 1c was better simulated by two species in chemical exchange (see Table 3; correlation coefficient $\mathrm{R}$ of simulation is about 0.96 when it is about 0.90 by using only one species) with a C-P bond in between pseudo-axial and bisectional orientation. The two signals were assigned to the trans diastereoisomer adduct. The occurrence for this nitrone also of the conformational exchange is a proof that it is due the rotations around the $\mathrm{C}_{2}-\mathrm{O}$ bond or the $\mathrm{O}-\mathrm{O}$ bond. Nevertheless, the average geometries of the two conformer sets in slow exchange looked like more envelopes than twist geometries $\left({ }^{3} \mathrm{E}\right.$ for one conformer set and $\left(<{ }^{3} \mathrm{E}-{ }^{3} \mathrm{~T}_{4}\right\rangle$ for the other set of the $2 \mathrm{R}, 4 \mathrm{~S}, 5 \mathrm{R}$ - adduct $\underline{\mathbf{8}}-\mathrm{OOH}_{\mathrm{t}}$; see Scheme 4) with HOO- group pseudo-axial but $-\mathrm{CH}_{2} \mathrm{OH}$ equatorial. This nitroxide had the smallest coupling constants $A_{P}$ observed for trans adduct in our nitrone series. Therefore, the weak intensity of the signal could be attributed to the degradation of the nitrone itself as to a weak persistency of the superoxide adduct because of its geometry inducing a too weak stabilization by anomeric or hyperconjugative effects. When using the $\left[\mathrm{KO}_{2} /\right.$ crown ether] generating system in the presence of $\underline{\mathbf{8}}$, the observed spectra were more complex because of the superimposition of three signals. One signal was assigned to the superoxide adduct; the second was assigned to one diastereoisomer adduct of the hydroxyl radical, and the third, to one of its degradation species.

The trapping of superoxide with nitrone 3-HMDEPMPO $\underline{\mathbf{6}}$ (fig 1d) led also to complicated spectra owing the formation of two diastereoisomer adducts of the diastereoisomer $\underline{\mathbf{6 t}}$ (94\% of $\underline{\mathbf{6}}$ ) but also of minor nitroxides $(10 \%)$ that could be issued from decomposition of the superoxide adducts or from adducts on $\underline{\mathbf{6 c}}$. The main signals of the spectra (fig 1d) observed for the 3 HMDEPMPO nitrone were therefore simulated by two pairs of signals (see Table 4). Each pair of signals described the signals of two species in slow chemical exchange. Because the high phosphorus coupling constants, one of these signal pairs could be assigned to the trans adduct $\underline{\mathbf{6 t}}-\mathrm{OOH}_{\mathrm{t}}$. It appeared in some average geometries distorted from the twist geometry because the $\mathrm{OOH}$ or the phosphorus group could be less pseudo-axial when the hydroxylmethyl groups is equatorial $\left(\left\langle{ }^{3} \mathrm{E}^{3}{ }^{3} \mathrm{~T}_{4}\right\rangle\right.$ or $\left\langle{ }^{3} \mathrm{~T}_{4}-\mathrm{E}_{4}\right\rangle$ conformations for $\mathrm{T}_{1}$ or $\mathrm{T}_{2}$ respectively of the $2 \mathrm{R}, 3 \mathrm{~S}, 5 \mathrm{R}$-adduct). The minor signal pear was assigned to the cis-adduct 6t-OOH ${ }_{c}$ in a twist geometry $\left(\left\langle{ }^{4} \mathrm{~T}_{3}\right\rangle\right.$ conformations for $\mathrm{T}_{1}$ and $\mathrm{T}_{2}$ of the $2 \mathrm{~S}, 3 \mathrm{~S}, 5 \mathrm{R}$-adduct) with the $\mathrm{OOH}$ group pseudo-axial/ bisectional when the hydroxymethyl group is axial and the phosphorus group is pseudo-equatorial. The simulation proved also lower values of the exchange rates between the conformer sets of the trans adduct when compared to $\underline{\mathbf{7 c}}-\mathrm{OOH}_{\mathrm{t}}$ conformers, traducing the effect of the $\mathrm{C}_{3}$ substitution, trans versus the phosphoryl group, and the modification of the neighborhood of the $\mathrm{OOH}$ moiety. These results were coherent with the observations done in the case of the analogue nitrone, 3-PhDEPMPO.

(b) Spin Trapping of some peroxyl radicals: Trapping of the methylperoxyl radical in aqueous medium was investigated with $4-\mathrm{HM}_{\mathrm{cis}} \mathrm{DEPMPO} \underline{\mathbf{7 c}}$ in a comparison aim of the signal shape of its adduct with that of superoxide adduct. The methylperoxyl radical was generated in aqueous buffer by oxidation of the methyl radical formed by attack of the hydroxyl radical on DMSO. The eight-line signal (major signal in fig 2a) of its adduct with nitrone $\underline{\mathbf{7 c}}$ showed a strong broadening of the internal lines of each quartet and a high dissymmetry that suggest again the presence of two conformers for one diastereoisomer adduct (trans) of this peroxyl radical. It was satisfactorily simulated with this assumption (Table 1) and was found superimposed to traces of the methyl radical adduct. 
Table 4 Esr parameters at $298 \mathrm{~K}$ of several radical adducts with 3-HMDEPMPO mainly at 298K.

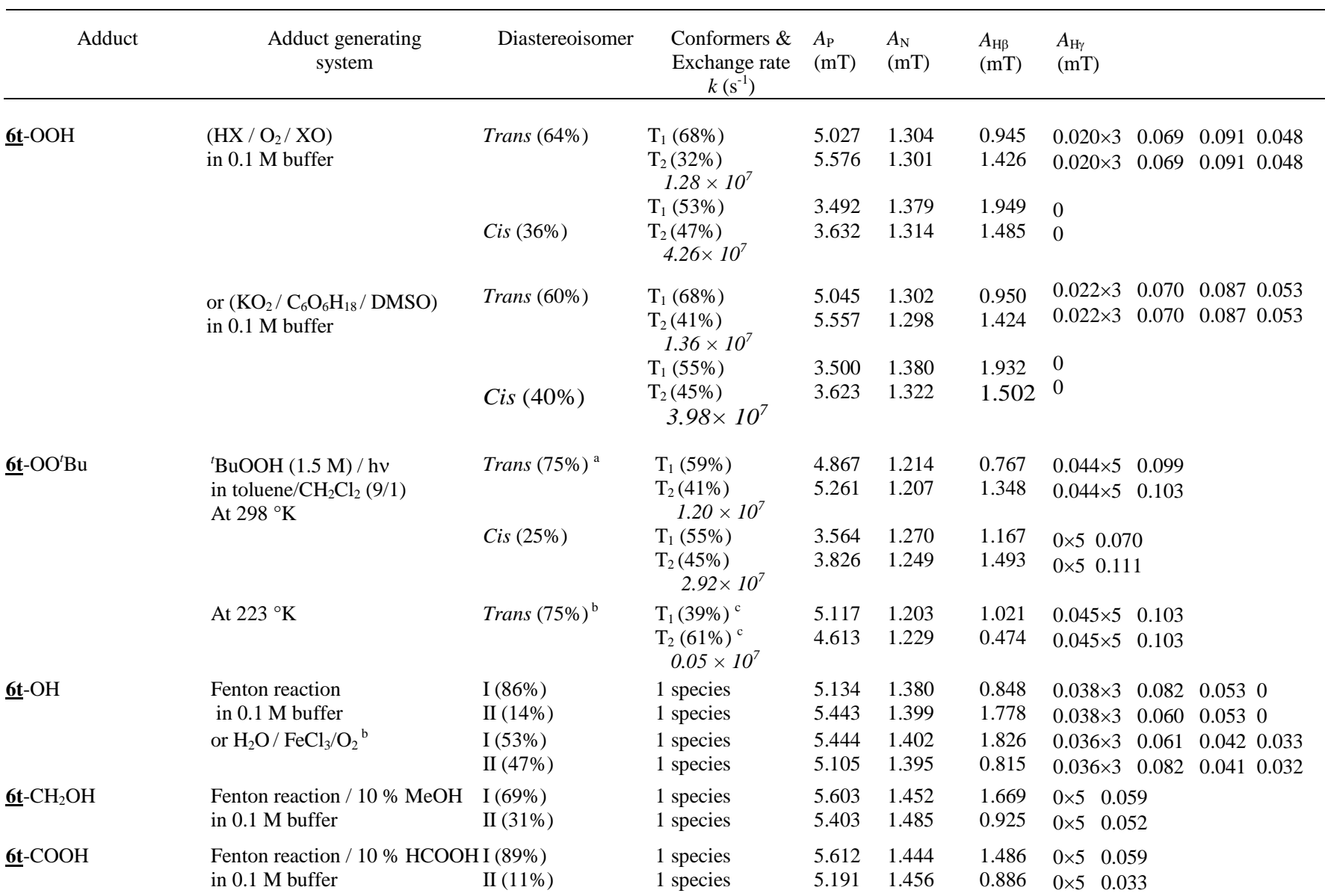

The regression coefficient Rof each simulation is $R>0.983 .{ }^{a}$ Classical Simulation $;{ }^{b}$ two dimensional simulation.

The conformers sets of adduct $\underline{\mathbf{7 c}}-\mathrm{OOMe}$ adopt similar averaged geometries than the superoxide adduct conformers: a twist geometry for the major conformer set $\left({ }^{3} \mathrm{~T}_{4}\right.$ for $2 \mathrm{R}, 4 \mathrm{~S}, 5 \mathrm{R}$ nitroxyde) and a twisted distorted-bent average geometry for the minor conformer set $\left(<{ }^{3} \mathrm{E}^{3} \mathrm{~T}_{4}\right\rangle$ for the $2 \mathrm{R}, 4 \mathrm{~S}, 5 \mathrm{R}$-nitroxyde). However, the C-P bond of $\underline{\mathbf{7 c}}-\mathrm{OOMe}$ was found slightly more bisectional than that of $\underline{\mathbf{7 c}}-\mathrm{OOH}$.

The trapping of the tert-butylperoxl radical in an organic medium such as toluene-dichloromethane (9/1) was investigated as it allowed to study the conformational exchange by varying the temperature and to approach the thermodynamic and kinetic parameters of this exchange at low temperature. This trapping was tested with $\underline{\mathbf{7 c}}$ and $\underline{\mathbf{6}}$ as it offered a new comparison view on the ring substitution effect. A classical simulation with the ROKI program ${ }^{13}$ of the signal observed at room temperature was done for each nitrone. This program was also used for a two dimensional simulation (field- temperature) of the whole set of the spectra recorded at various temperatures. The simulation was done by optimizing the set of coupling constants and the thermodynamic parameters such as, the average activation energy between the two conformers, the preexponential factor of the Arrhenius relation, the entropy and enthalpy terms. ${ }^{21}$ This simulation method allowed to obtain the coupling constant values of the two conformers, their populations $p_{i}$ and their exchange period $\tau_{i}$ at the various temperatures and to calculate the value of the exchange rate $(\mathrm{k}$ $\left.=\mathrm{p}_{1} \times 1 / \tau_{1}+\mathrm{p}_{2} \times 1 / \tau_{2}\right)$. In tables 1 and 4 , the parameters are given at $283^{\circ} \mathrm{K}$ and, above all, at $223^{\circ} \mathrm{K}$, where, due to the slowest exchange (lowest kinetic rate), the most reliable hf constants for the conformational analysis can be obtained. The resulting spectrum with $\underline{\mathbf{7 c}}$ proved a stereo-selective addition of 
the $\mathrm{tBuOO} \bullet$ radical and the signal of the resulting trans adduct was also an eight-line signal with a dissymmetry quite similar to that of the $\mathbf{7 c}-\mathrm{OOH}$ signal in buffer. The signal of this peroxyl adduct $\underline{\mathbf{7 c}}-\mathrm{OO}^{t} \mathrm{Bu}_{\mathrm{t}}$ was studied at various temperature from $223 \mathrm{~K}$ to $308 \mathrm{~K}$, (three examples are given in Figure $2 \mathrm{~b}$ to d). A broadening of the lines and an increase of dissymmetry was observed with decrease of temperature. This reversible change confirmed the model of two conformers for peroxyladducts. The major conformer with the larger $A_{P}$ and $A_{H}$ values adopts, at any temperatures, a distorted twist-bent average geometry $\left({ }^{3} \mathrm{E}^{3} \mathrm{~T}_{4}\right\rangle$ for the $2 \mathrm{R}, 4 \mathrm{~S}, 5 \mathrm{R}$-adduct $\left.\underline{\mathbf{7 c}}-\mathrm{OO}^{\mathrm{t}} \mathrm{Bu}_{\mathrm{t}}\right)$ when the minor conformer adopts the bent average geometry $\left({ }^{3} \mathrm{E}\right.$-like for the $2 \mathrm{R}, 4 \mathrm{~S}, 5 \mathrm{R}$-adduct) with in both cases a pseudo-axial $\mathrm{C}_{2^{-}}$ $\mathrm{OOtBu}$ orientation. This orientation can stabilize nitroxide moiety by an anomeric interaction, because of a strong hyperconjugative interaction of the $\sigma^{*}\left(\mathrm{C}_{2}-\mathrm{O}\right)$ bond with the $\pi$ $\left(\mathrm{N}-\mathrm{O}^{\bullet}\right)$. If compared with trans DEPMPO-OO ${ }^{t} \mathrm{Bu}$ adduct, ${ }^{22}$ the cis $\mathrm{C}_{4}$-substitution by the hydroxymethyl group does not affect the average geometries of the conformers sets nor the exchange rate. The hydroxymethyl group can have an outer-ring orientation minimizing its interaction with the cis phosphoryl group.

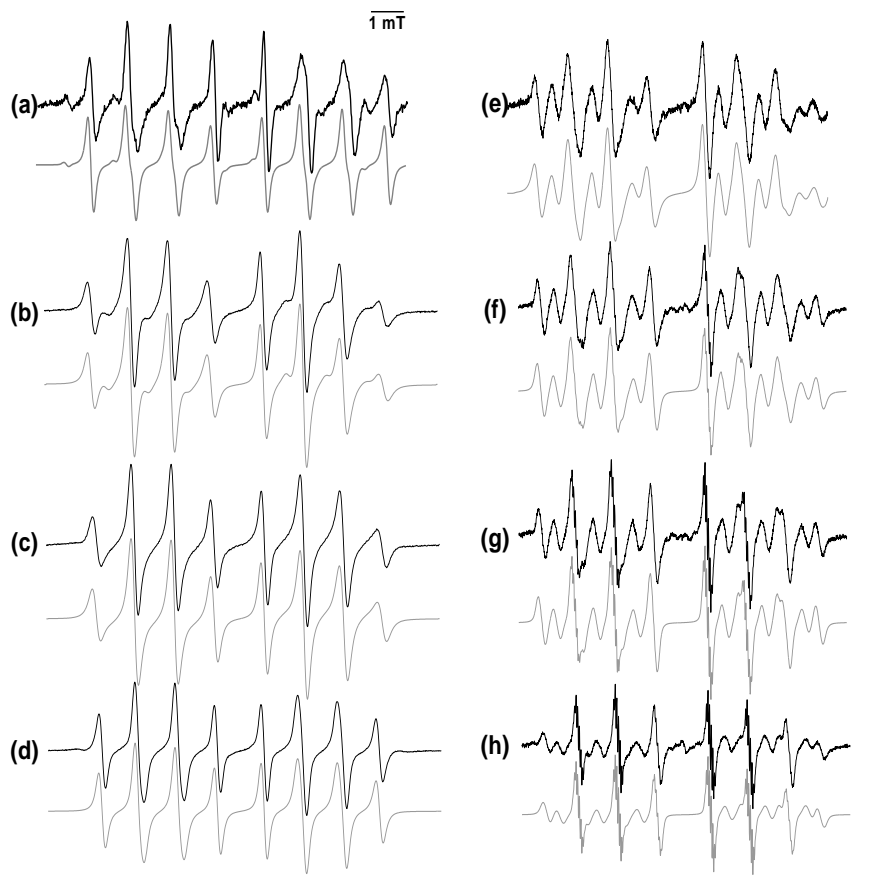

Figure 2. Spin trapping of peroxyl radicals with nitrones $\underline{7 c}$ or $\underline{6}$. Spectrum (dark lines) obtained and simulated (grey lines) from a mixture containing (a) $7 \mathbf{c}(10 \mathrm{mM}), \mathrm{H}_{2} \mathrm{O}_{2}(2 \mathrm{mM}), \mathrm{FeSO}_{4}(2 \mathrm{mM})$, DTPA. (1 mM), DMSO (5\%) in phosphate buffer $(0.1 \mathrm{M}), \mathrm{pH} 7.3$ after 1 min incubation under $\mathrm{O}_{2}$ atmosphere. (b) $\mathbf{7 c}(20 \mathrm{mM})$ and ${ }^{t} \mathrm{BuOOH}(1.5 \mathrm{M})$ in deoxygenated toluene $/ \mathrm{CH}_{2} \mathrm{Cl}_{2}(9 / 1) \mathrm{UV}$-photolysed at $223 \mathrm{~K}$. (c) as (b) at $258^{\circ} \mathrm{K}$. (d) as (b) at $298^{\circ} \mathrm{K}$. (e) as (b) but with $\underline{6}$ at $223^{\circ} \mathrm{K}$. (f) as (b) but with $\mathbf{6}$ at $243^{\circ} \mathrm{K}$. (g) as (b) but with $\underline{\mathbf{6}}$ at $263^{\circ} \mathrm{K}$. (h) as (b) but with $\underline{\mathbf{6}}$ at $283^{\circ} \mathrm{K}$ Spectrometer settings: microwave power, $10 \mathrm{~mW}$; modulation amplitude, $0.497 \mathrm{mT}(a), 0.217 \mathrm{mT}$ $(b-d), 0.124 \mathrm{mT}(e-h)$; time constant, $0.28 \mathrm{~ms}(a), 0.64 \mathrm{~ms}(b-h)$; gain $10^{5}(a)$, $8 \times 10^{4}(b-d), 5 \times 10^{4}(e-h)$; sweep time, $84 s(a), 167.77 s(b-d), 671 s(e-h)$; conversion time, $82 \mathrm{~ms}(a), 163.84 \mathrm{~ms}(b-d), 655.36 \mathrm{~ms}(e-h)$.
As for superoxide, the trapping, with $\underline{\mathbf{6}}$, of ${ }^{t} \mathrm{BuOO}^{\bullet}$ radicals in toluene-dichloromethane (9/1) led to complicated spectra owing the formation of two diastereoisomer adducts of the diastereoisomer $\underline{\mathbf{6 t}}$ with the preponderance, however, of the trans adduct. A temperature study of the signal shape afforded the spectra given in Fig. $2 \mathrm{e}, 2 \mathrm{f}, 2 \mathrm{~g}$ and $2 \mathrm{~h}$. The signals of $\underline{6}-$ $\mathrm{OO}^{\mathrm{t}} \mathrm{Bu}$ (Fig. 2h) exhibited at ambient temperature and even below visible $\gamma_{\mathrm{AH}}$ hyperfine coupling constants that allowed an accurate simulation of both signals (table 4). At the low temperature of $223^{\circ} \mathrm{K}$, the signals are broadened and the hyperfine lines disappeared (Fig. 2e).

The major conformer of the trans adduct $\underline{6}-\mathrm{OO}^{\mathrm{t}} \mathrm{Bu}_{\mathrm{t}}$ (minor at $298^{\circ} \mathrm{K}$ ) adopts a bent geometry $\left({ }^{3} \mathrm{E}\right.$ for the $2 \mathrm{R}, 3 \mathrm{~S}, 5 \mathrm{R}$-adduct) with a strongly equatorial $\mathrm{C}_{2}-\mathrm{H}$ bond when the second conformer adopts a twist conformation $\left({ }^{3} \mathrm{~T}_{4}\right.$ for the $2 \mathrm{R}, 3 \mathrm{~S}, 5 \mathrm{R}-$ adduct). In the bent geometry conformation, the axial orientation of $\mathrm{OOtBu}$ makes its steric interaction strong with the pyrroline ring while stabilizing the nitroxyde by an anomeric interaction. While the phosphorous and hydrogen couplings are smaller compared to the values of DEPMPO, the exchange correlation times (not given herein) are very long at $223^{\circ} \mathrm{K}$, and therefore, the exchange rate is slowed at this low temperature. The value of the exchange kinetic constant of 6t- $^{-}$ $\mathrm{OO}^{t} \mathrm{Bu}_{\mathrm{t}}$ is smaller than those calculated for $\underline{\mathbf{7 c}}-\mathrm{OO}^{\mathrm{t}} \mathrm{Bu}$.The thermodynamic parameters of the conformational exchange between the ${ }^{t} \mathrm{BuOO}^{\bullet}$ adducts with $\underline{\mathbf{7 c}}$ or $\underline{\mathbf{6}}$ calculated at $223 \mathrm{~K}$ are given in Table 5. The rate of $\mathrm{OO}^{\mathrm{t}} \mathrm{Bu}$ rotation is strongly affected by the pseudo-rotation of pyrroline ring. The energy barrier of this $\mathrm{OO}^{t} \mathrm{Bu}$ rotation is increased by the substitution at $\mathrm{C}_{4}$ in comparison with DEPMPO-OO ${ }^{t} \mathrm{Bu}$. This is evidenced by the slightly larger $\mathrm{E}_{\mathrm{a}}$ or $\Delta \mathrm{H}^{\# 2}$ values, but the impact on the entropy $\Delta S^{\#}$ is more important and just compensate for $\underline{\mathbf{7 c}}$ the hindering effect of a larger barrier. Therefore, the $\Delta G^{\#}$ free energy of barrier is the same than for DEPMPO-OO ${ }^{t} \mathrm{Bu}$.

The steric interaction is strongly magnified if the pyrroline ring has a substituent on the position 3 with a cis-orientation with respect to the OOtBu group. This fact is indicated in the above table by the very large $\mathrm{E}_{\mathrm{a}}$ and $\Delta \mathrm{H}^{\#}$ values of $\underline{\mathbf{6}}-\mathrm{OO}^{\mathrm{t}} \mathrm{Bu}$. Though the $\Delta \mathrm{G}^{\#}$ free energy of barrier is also increased compared to the non-substituted pyrroline ring at the position 3 , the difference is not as large, since the transition state is entropically disfavored (see $\Delta S^{\#}$ ). The reduced entropy difference is caused primarily

Table 5. Thermodynamic parameters at $223 \mathrm{~K}$ of the tBuOO• radical adduct of nitrones DEPMPO, $\underline{\mathbf{7}}$ and $\underline{\mathbf{6}}$

\begin{tabular}{|c|c|c|c|}
\hline Adduct & DEPMPO- $\mathrm{OO}^{t} \mathrm{Bu}$ & $\underline{7 c}-\mathrm{OO}^{t} \mathrm{Bu}$ & $\underline{\mathbf{6}}-\mathrm{OO}^{t} \mathrm{Bu}$ \\
\hline$\Delta \mathrm{H}_{\mathrm{R}}^{1,2}$ in $\mathrm{kJ} . \mathrm{M}^{-1}$ & 0.20 & 0.64 & -2.07 \\
\hline$\Delta \mathrm{S}_{\mathrm{R}}^{1,2}$ in $\mathrm{J} . \mathrm{K}^{-1} \mathrm{M}^{-1}$ & -6.50 & -12.71 & -5.43 \\
\hline$\Delta \mathrm{G}_{\mathrm{R}}^{1,2}$ in $\mathrm{kJ} . \mathrm{M}^{-1}$ & 1.73 & 3.15 & -0.46 \\
\hline$\Delta \mathrm{H}^{\# 2}$ in $\mathrm{kJ} \cdot \mathrm{M}^{-1}$ & 11.41 & 14.99 & 26.39 \\
\hline $\mathrm{E}_{\mathrm{a}}{ }^{1}$ in $\mathrm{kJ} \cdot \mathrm{M}^{-1}$ & 13.50 & 15.14 & 27.31 \\
\hline$\Delta \mathrm{S}^{\# 2}$ in $\mathrm{J} \cdot \mathrm{K}^{-1} \cdot \mathrm{M}^{-1}$ & -58.11 & -44.93 & -15.30 \\
\hline$\Delta \mathrm{G}^{\# 2}$ in $\mathrm{kJ} . \mathrm{M}^{-1}$ & 28.73 & 28.38 & 30.95 \\
\hline \multicolumn{4}{|c|}{$\begin{array}{l}{ }^{a} \text { Calculated by the Arrhenius plus Van t'Hoff equations } \\
{ }^{b} \text { calculated by the Eyring plus Van t'Hoff equations }\end{array}$} \\
\hline
\end{tabular}


by the entropy loss of conformers between which the transition takes place. The above observations reveal that the jump of $\mathrm{OO}^{\mathrm{t}} \mathrm{Bu}$ rotamer, from one stable orientation to the other, is almost equally blocked energetically and entropically, but the entropic effect is reduced for substitution both at position 4 and 3 , but in the latter case the effect is more important. The two rotamers of of $\underline{\mathbf{7 c}}-\mathrm{OO}^{t} \mathrm{Bu}$ have closely identical energy (see the small $\Delta H_{R}$ values), but their populations are more significantly affected by the adaptation of ring geometry to the orientation of OOtBu group (see the variation of $\Delta S_{R}$ ). For $\underline{7 c}-O^{t} B u$ the adaptation is not really efficient $\left(\Delta S_{R}\right.$ is increased). Interestingly, the two conformers of $\underline{\mathbf{6 t}}-\mathrm{OO}^{\mathrm{t}} \mathrm{Bu}$ are affected from entropic point of view, in the same amount: the $\Delta S_{R}$ values of adducts DEPMPO-OO ${ }^{t} \mathrm{Bu}$ and $\underline{\mathbf{6 t}}-\mathrm{OO}^{\mathrm{t}} \mathrm{Bu}$ are nearly equal. The broader energetical gap traduced by higher values of the average activation energy between the two conformers sets for $\mathbf{7 c}-\mathrm{OO}^{t} \mathrm{Bu}$ and particularly for $\mathbf{6}-\mathrm{OO}^{t} \mathrm{Bu}$ adducts explained the preponderance of one conformer set when compared with DEPMPO-OO ${ }^{t} \mathrm{Bu}$ adduct but also the slower exchange rate at low temperature for $\mathbf{6}-\mathrm{OO}^{t} \mathrm{Bu}$.

(c) Spin Trapping of the hydroxyl radical: The hydroxyl radical was generated in phosphate buffer at $\mathrm{pH} 7.3$ using hydrogen peroxide and ferrous sulphate (Fenton system). Incubation of the nitrones with the hydroxyl radical generating system led to the ESR signals given in Fig. 3. We verified the complete inhibition of signal when catalase was added to the generating mixture. Assignment of some signals in each spectrum recorded for each nitrone to the corresponding hydroxyl adduct was supported by comparison with the signals observed after oxidation (by oxygen) of the hydroxylamines formed by the nucleophilic addition of water on nitrones in the presence of iron III ( $\left.\mathrm{FeCl}^{\mathrm{III}} 0.5 \mathrm{mM}\right)$.

Once again the spectra obtained in Fenton experiments with the cis diastereisomer $\underline{\mathbf{7 c}}$ were more intense and simpler than those obtained with the other nitrones. The solvated hydroxyl radical was expected to attack $\underline{\mathbf{7 c}}$ on the side opposite to the diethoxyphosphoryl group. The major 12 lines signal in Fig. 3a, had indeed the $A_{P}$ and $A_{H}$ values characteristic for pseudo-axial phosphoryl and hydroxyl orientations in a twist structure $\left({ }^{3} \mathrm{~T}_{4}\right.$ for $2 \mathrm{R}, 4 \mathrm{~S}, 5 \mathrm{R}$-nitroxyde) that could be assigned to the trans hydroxyl adduct $\underline{\mathbf{7 c}-\mathrm{OH}_{\mathrm{t}}}$. The more crowded $\mathrm{cis} \mathrm{HO}^{\bullet}$ adduct $\underline{\mathbf{7 c}-}$ $\mathrm{OH}_{c}$ led to a minor signal $(13 \%)$ with the $\mathrm{A}_{\mathrm{P}}$ and $\mathrm{A}_{\mathrm{H}}$ values indicating a more axial phosphoryl group for a orientation more bisectional of the $\mathrm{C}_{2}-\mathrm{H}$ and therefore a distorted twist geometry to bent geometry $\left({ }^{3} \mathrm{~T}_{4}-\mathrm{E}_{4}\right\rangle$ like structure for $2 \mathrm{~S}, 4 \mathrm{~S}, 5 \mathrm{R}$ nitroxyde). The signal of this cis adduct was superimposed in a higher percentage $(30 \%)$ to the signal of $\underline{\mathbf{z c}}-\mathrm{OH}_{t}$, in the spectrum observed after nucleophilic addition of water on $\underline{\mathbf{7 c}}$ and subsequent oxidation of the hydroxylamine formed (Fig $3 b)$. In both experiments the signal of the cis adduct increased with time of incubation when the signal of trans adduct decreased.

7c-OH can be obtained by transformation of the superoxide adduct $\mathbf{7 c - O O H}$ (Fig. 3c) by addition of glutathion peroxydase (GPO) with reduced glutatione (GSH) in the reaction mixture.
In this experiment the trans adduct $\underline{\mathbf{7 c}-\mathrm{OH}_{\mathrm{t}}}$ was observed with only a trace of $\mathbf{7} \mathbf{c}-\mathrm{OH}_{\mathrm{c}}(<5 \%)$. This result confirmed the almost exclusive trans addition of superoxide on nitrone $\underline{\mathbf{7 c}}$.

Two minor signals were also superimposed to the $\underline{\mathbf{7 c}-O H}$ signals in the spectrum issued from the Fenton experiment (fig $4 \mathrm{a})$. They were assigned to $\underline{\mathbf{A}}\left(11 \%, \mathrm{~A}_{\mathrm{N}}=1.415 \mathrm{mT}, \mathrm{A}_{\mathrm{P}}=\right.$ $\left.5.756 \mathrm{mT}, \mathrm{a}_{\mathrm{H} \beta}=1.948 \mathrm{mT}\right)$, and $\underline{\mathbf{B}}\left(6 \%, \mathrm{~A}_{\mathrm{N}}=1.516 \mathrm{mT}, \mathrm{A}_{\mathrm{P}}=\right.$ $\left.6.099 \mathrm{mT}, \mathrm{a}_{\mathrm{H} \beta}=2.298 \mathrm{mT}\right)$, two adducts on $\underline{\mathbf{7 c}}$. The nitroxide $\underline{\mathbf{B}}$ increased to $27 \%$ after $1 \mathrm{~h} 30$ incubation. From their coupling constant values, $\underline{\mathbf{A}}$ and $\underline{\mathbf{B}}$ appeared carbon centred radical adducts (cf. next paragraph) because of their high $\mathrm{a}_{\mathrm{H} \beta}$ values denoting pseudoaxial $\mathrm{C}_{2}-\mathrm{H}$. However, $\underline{\mathbf{B}}$ was assigned to a cis adduct because of tallest $A_{p}$ and $a_{H}$ values $\left(<{ }^{3} T_{4}-E_{4}\right\rangle$ for the $2 \mathrm{~S}, 4 \mathrm{~S}, 5 \mathrm{R}$-adducts). when $\underline{\mathbf{A}}$ was assigned to a trans adduct (in $\mathrm{E}_{4}$-like geometry for the $2 \mathrm{R}, 4 \mathrm{~S}, 5 \mathrm{R}$-adducts). $\underline{\mathbf{A}}$ and $\underline{\mathbf{B}}$ might be issued from the addition on nitrone $\underline{\mathbf{7 c}}$ of a radical resulting from one hydrogen abstraction on the hydroxylmethyl substituent of a second $\underline{\mathbf{7 c}}$ molecule (see Scheme 5). The hydrogen bonding between the hydroxyl groups of the two molecules involved can reinforced the cis-addition.
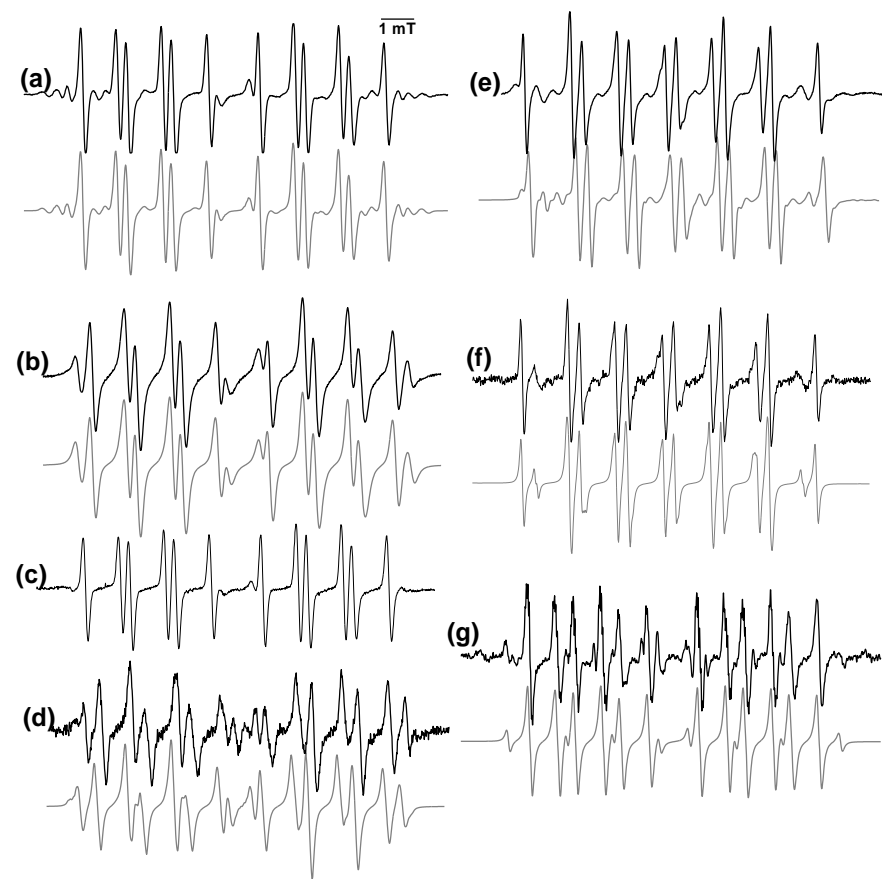

Figure 3. ESR signals of hydroxyl radical adduct with nitrones $\underline{7 c}$ and $\mathbf{7 t}, \underline{8}$ and $\underline{6}$. Spectra obtained (dark lines) and computer simulated (gray lines) after incubation (a) $1 \mathrm{~min}$ of $\underline{\mathbf{7 c}}(61 \mathrm{mM})$ in phosphate buffer $0.1 \mathrm{M}$, at $\mathrm{pH}$ 7.3 containing $\mathrm{H}_{2} \mathrm{O}_{2}(2 \mathrm{mM}), \mathrm{FeSO}_{4}(2 \mathrm{mM})$, DTPA $(1 \mathrm{mM})$. (b) $10 \mathrm{~min}$ of 7c $(20 \mathrm{mM}) . \mathrm{FeCl}^{\mathrm{III}} 0.5 \mathrm{mM}$ in pure water. (c) 9 min of $\underline{\mathbf{7 c}}(61 \mathrm{mM})$ in phosphate buffer $0.1 \mathrm{M}$, at $\mathrm{pH} 7.3$ containing $\mathrm{HX}(0.4 \mathrm{mM})$, XO $(0.04 \mathrm{U}$ $\left.\mathrm{mL}^{-1}\right)$, DTPA $(1 \mathrm{mM})$, to which then GPO $(10 \mathrm{mM})$ and GSH $(1.2 \mathrm{mM})$ were added. (d) as (a) but with $\underline{\mathbf{8}}(50 \mathrm{mM})$. (e) as (a) but with $\underline{7 \mathrm{t}}(50 \mathrm{mM})$. (f) as (b) but with $\underline{\mathbf{7 t}}(20 \mathrm{mM})$. (g) as (a) but with $\underline{\mathbf{6}}(50 \mathrm{mM})$. Spectrometers settings: microwave power $10 \mathrm{~mW}$; modulation amplitude, $0.497(a-f), 1$ (g); time constant, $0.128 \mathrm{~s}$; gain 105; sweep time, $83.89 \mathrm{~s}$; conversion time, $82 \mathrm{~ms}$.

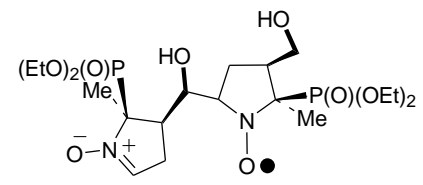


Scheme 5. General chemical structure of $\underline{A}$ and $\underline{B}$.

The spectrum (Fig 3e) observed after incubation of the other diastereoisomer $\underline{\mathbf{7 t}}$ with hydroxyl radicals showed superimposition of two signals that were both assigned to the hydroxyl adduct in two diastereoisomeric forms (Table 3). The ratio between the two diastereoisomers was almost the same after nucleophilic addition of water in presence of iron III and subsequent oxidation of the hydroxylamine formed (Fig 3f). The major adduct was assigned to the cis-adduct $\mathbf{7 t}-\mathrm{OHc}$ in a twist average geometry with $\mathrm{C}_{2}-\mathrm{H}$ bond in between pseudo equatorial and bisectional orientation $\left(\left\langle{ }^{4} \mathrm{~T}_{3^{-}}\right\rangle\right.$for $2 \mathrm{~S}, 4 \mathrm{R}, 5 \mathrm{R}-$ nitroxyde). The minor trans -adduct $\mathbf{7 t}-\mathrm{OHt}$ was found in a bent average geometry with axial $\mathrm{C}_{2}-\mathrm{H}$ bond and a bisectional C-P bond ( ${ }^{3}$ E-like for 2R,4R,5R-nitroxyde).

Incubation of the hydroxyl radical generating system in the presence of the cyclic nitrone MEOOPPO $\underline{\mathbf{8}}$ led to a spectrum (Fig 4d) that was satisfactorily simulated assuming the presence of three species. The major signal was assigned to the trans adduct $\underline{\mathbf{8}}-\mathrm{OHt}$ adduct in a bent average geometry with axial $\mathrm{C}_{2}$ $\mathrm{H}$ bond and a bisectional C-P bond $\left({ }^{3} \mathrm{E}-\mathrm{like}\right.$ for $2 \mathrm{R}, 4 \mathrm{~S}, 5 \mathrm{R}-$ nitroxyde). The minor cis adduct presented a relatively low phosphorus coupling constant in respect to its high hydrogen coupling constant (Table 3). Therefore, this adduct was found in an twist average geometry with a $\mathrm{C}$-P bond more bisectional than pseudo-axial et $\mathrm{C}_{2}-\mathrm{H}$ bond more bisectional than pseudoequatorial $\left({ }^{5} \mathrm{~T} 4\right.$ for $2 \mathrm{~S}, 4 \mathrm{~S}, 5 \mathrm{~S}$-nitroxyde). The third species with $\mathrm{C}_{2}-\mathrm{H}$ bond more bisectional was not defined $\left(15 \%, \mathrm{~A}_{\mathrm{N}}=1.439\right.$ $\left.\mathrm{mT}, \mathrm{A}_{\mathrm{P}}=5.191 \mathrm{mT}, \mathrm{A}_{\mathrm{H} \beta}=2.131 \mathrm{mT}\right)$. Adducts on $\underline{\mathbf{8}}$ of carbon centred species were proved to exhibit an higher phosphorus coupling constant. Because of the relatively fast disappearances of both hydroxyl adducts, this persistent third species was proved to be of another nature.

The nitrone $\underline{\mathbf{6}}$ afforded in the presence of hydroxyl radicals a spectrum (Fig 3f) composed with two major signals with very different $a_{H \beta}$ values (Table 4) and closed $A_{P}$ and $A_{N}$ and $g$ values assigned to the major trans and the minor cis $\mathrm{OH}-$ adducts on $\underline{6 t}$. Both signals were recorded after the nucleophilic addition of water in the presence of $\mathrm{Fe}^{\mathrm{III}}$ but in different percentage. They are each in a twist distorted average geometry $\left(<{ }^{3} \mathrm{E}^{-}{ }^{3} \mathrm{~T}_{4}\right\rangle$ for the major signal $2 \mathrm{R}, 3 \mathrm{R}, 5 \mathrm{R}$-adduct $\underline{\mathbf{6 t}}-\mathrm{OH}_{\mathrm{t}}$ and $<^{3} \mathrm{~T}_{4}-\mathrm{E}_{4}>$ for the minor signal assigned to $2 \mathrm{~S}, 3 \mathrm{R}, 5 \mathrm{R}$-adduct $\underline{\mathbf{6 t}}-$ $\left.\mathrm{OH}_{\mathrm{c}}\right)$. Another little signal was also involved in each spectrum (15\% for Fenton experiment and $4 \%$ for nucleophilic addition; $\mathrm{A}_{\mathrm{N}}=1.45 \mathrm{mT}, \mathrm{A}_{\mathrm{P}}=5.83 \mathrm{mT}, \mathrm{A}_{\mathrm{H} \beta}=1.44 \mathrm{mT}$ ) resulting probably from the degradation of the first species.

(d) Spin-Trapping of centred radicals: some minor species observed when the hydroxyl radical was generated might be due to the trapping of several carbon centred radicals. Since the hydroxyl radical can easily abstract hydrogen atoms on the $\alpha$ carbon atom of an alcohol, the reactivity of the hydroxyl radical towards the hydroxymethyl group of the pyrroline ring may be involved. Therefore, we studied the trapping of various carbon centred radicals generated by a hydrogen abstraction on $\mathrm{C}-1$ of alcohol (methanol or ethanol) or acid $(\mathrm{HCOOH})$ or by the scission of the C-S bond of DMSO (affording the methyl radical). We report, in Fig. 4, the spectra observed after the trapping of these various carbon centred species by $\underline{7 c}$. A residual trace of the trans hydroxyl adduct can be seen sometimes in the spectra. For comparison, the spectrum observed after the prolonged incubation of $\underline{\mathbf{7 c}}$ in the Fenton experiment showing also the presence of adduct $\underline{\mathbf{B}}$ (cited before) was given in Fig. 4a. In the experiments of Fig 4b, c, d, and e, the main signals of the spectrum issued for the carbon centred radical trapping were relatively simple, and at first view can be assigned to only one species although the assymetric internal lines.

We investigated the trapping of carbon centred radicals with the others nitrones and generally two species diastereoisomer were obtained (Table 3 and 4). One example is given with nitrone $\underline{7 t}$ in Fig. 4f showing the complexity of the spectrum. The major adduct was assigned again to the cis adduct in a twist average geometry with $\mathrm{C}_{2}-\mathrm{H}$ bond in between pseudo-equatorial / bisectionnal orientation ( $\left\langle{ }^{4} \mathrm{~T}_{3^{-}}\right\rangle$for $2 \mathrm{~S}, 4 \mathrm{R}, 5 \mathrm{R}-$ nitroxyde). The trans adduct $\underline{7 \mathbf{t}}-\mathrm{CH}_{2} \mathrm{OH}_{\mathrm{t}}$ was found in a twist distorted average geometry $<{ }^{4} \mathrm{~T}_{3}-\mathrm{E}_{3}>$ conformation for $2 \mathrm{R}, 4 \mathrm{R}, 5 \mathrm{R}$-nitroxyde).

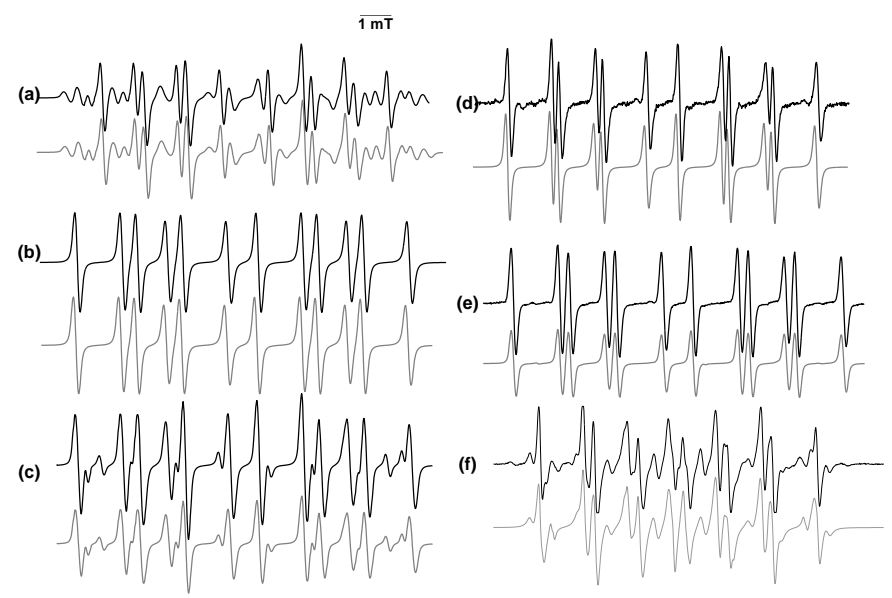

Figure 4. Spin trapping of carbon centred radicals by nitrone 4HMDEPMPO. Spectra obtained (dark lines) and computer simulated (gray lines) from phosphate buffer $\left(0.1 \mathrm{M}, \mathrm{pH} 7.3\right.$ containing $\mathbf{7 c}(61 \mathrm{mM}), \mathrm{H}_{2} \mathrm{O}_{2}(2$ $\mathrm{mM}), \mathrm{FeSO}_{4}(2 \mathrm{mM})$, DTPA $(1 \mathrm{mM})$ (a) after $1 \mathrm{~h} 30$ incubation; (b) after 3 min incubation in the presence of $\mathrm{MeOH}(10 \%)$; (c) after 1 min incubation in the presence of EtOH (10\%); (d) after 1 min incubation in the presence of $\mathrm{HCOOH}(10 \%)$. (e) after 10 min incubation in the presence of DMSO (5\%) under argon atmosphere; (f).as in (b) but in presence of $\mathbf{7 t}$. Spectrometers settings: microwave power $10 \mathrm{~mW}$; modulation amplitude, $0.497(a, b, e)$, $0.702(\mathrm{c}), 0.01(\mathrm{~d})$; time constant, $0.128 \mathrm{~s}$; gain $10^{5}$; sweep time, $83.89 \mathrm{~s}$; conversion time, $82 \mathrm{~ms}$.

By submitting alcohol or formiate to the action of the hydroxyl radical, in presence of $\underline{6}$ or $\underline{8}$, two signals (spectra not shown) were formed presenting close $g$ and $a_{N}$ values and high $A_{P}$ values (Tables 2 and 3 ) that can be explained by an axial or pseudo-axial orientation of the $\mathrm{C}-\mathrm{P}$ bond. For $\underline{\mathbf{8}}$ adducts, the high $\mathrm{a}_{\mathrm{H}}$ traduces a pseudo-axial orientations of $\mathrm{C}_{2}-\mathrm{H}$ bond of trans adduct and a $\mathrm{C}_{2}-\mathrm{H}$ bond bisectional for cis adduct. In contrary, the $\mathrm{a}_{\mathrm{H}}$ values differs for $\underline{\mathbf{6}}$ adducts with a pseudoequatorial orientation of $\mathrm{C}_{2}-\mathrm{H}$ for the trans-diastereoisomer in a minor ratio (small $\mathrm{a}_{\mathrm{H}}$ value $;\left\langle\mathrm{E}^{3}{ }^{3} \mathrm{~T}_{4}\right\rangle$ for the $2 \mathrm{R}, 3 \mathrm{R}, 5 \mathrm{R}$-adduct 
$\left.\underline{\mathbf{6 t}}-\mathrm{R}_{\mathrm{t}}\right)$ and a major cis-adduct with various orientations of the $\mathrm{C}_{2}-\mathrm{H}$ bond traducing possible hydrogen bonding of the hydroxylmethyl substituent with the group added.

\section{Degradation of the Superoxide adduct}

We already shown ${ }^{9}$ that the half-life time of $\underline{\mathbf{7}}-\mathrm{OOH}_{\mathrm{t}}$ was 21 min when the half-life time of adduct DEPMPO-OOH was 15 min 30 s and that the decay of the $\underline{\mathbf{7 c}}-\mathrm{OOH}$ has a predominant first order character. In comparison with the other nitrones of our series, its superoxide adduct is the more persistent. In experiments with both superoxide generating system systems and in spite of argon bubbling the decay of the signal of the superoxide adduct $\underline{\mathbf{7 c}}-\mathrm{OOH}$ was observed with increase of another nitroxide signal that was identified as the hydroxyl adduct. From the simulation of the spectra of Fig. 5a $(\mathrm{R}=0.988)$ and $6 \mathrm{~b}(\mathrm{R}=0.988)$ we admitted the involvement of $53 \%$ and $14.3 \%$ respectively of the trans hydroxyl adduct but also of $8.7 \%$ and $5.5 \%$ of the cis hydroxyl adduct respectively. The ratio of the cis hydroxyl adduct to the trans adduct was higher than that observed when the superoxide adduct was transformed into the hydroxyl adduct by the system [GPO / GSH].

(a)

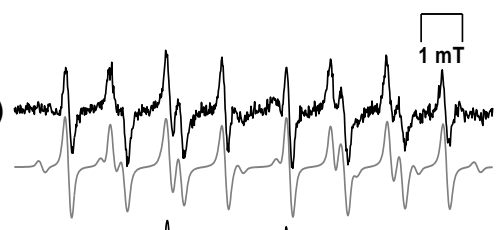

(b)

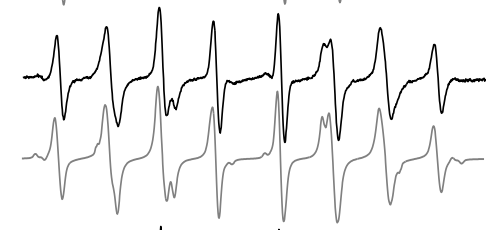

(c)

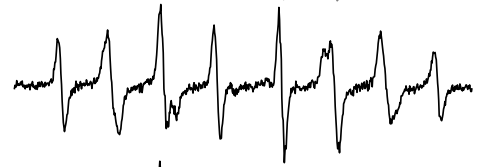

(d)

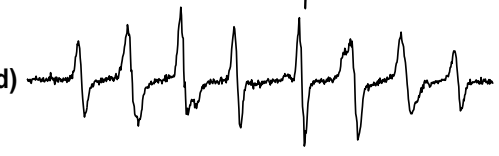

Figure 6. Evolution of observed (dark lines) and simulated (grey lines) spectra in superoxide trapping with $\underline{\mathbf{7 c}}$ (a) after $52 \mathrm{~min}$ incubation of $\underline{\mathbf{7 c}}$ $(50 \mathrm{mM})$ in phosphate buffer $\left(0.1 \mathrm{M}, \overrightarrow{\mathrm{pH}} 7.3\right.$ containing $\mathrm{KO}_{2}(10 \mathrm{mM}) /$ DMSO (10\%). (b) after $1 \mathrm{~h} 16$ incubation under argon bubbling of $\underline{7 \mathbf{c}}(61 \mathrm{mM})$ containing HX $(0.4 \mathrm{mM})$, XO $\left(0.04 \mathrm{U} \mathrm{mL}^{-1}\right)$, DTPA $(1 \mathrm{mM})$. (c) after $16 \mathrm{~min}$ incubation of $\underline{\mathbf{7 c}}(50 \mathrm{mM})$ and mannitol $(100 \mathrm{mM})$ in phosphate buffer $(0.1$ $\mathrm{M}, \mathrm{pH} 7.3)$ containing $\mathrm{KO}_{2}(10 \mathrm{mM}) / \mathrm{DMSO}(10 \%)$. (d) after $16 \mathrm{~min}$ incubation of $\underline{7 \mathbf{c}}(50 \mathrm{mM})$ and catalase $\left(100 \mathrm{U} \mathrm{mL}^{-1}\right)$ in phosphate buffer $(0.1$ $\mathrm{M}, \mathrm{pH}$ 7.3) containing $\mathrm{KO}_{2}(10 \mathrm{mM}) / \mathrm{DMSO}(10 \%)$. Spectrometers settings: microwave power $10 \mathrm{~mW}$ (a-e); modulation amplitude, $0.313(a-b), 0.702$ (c), 0.22 (d-e); time constant, $1.28 \mathrm{~ms}$ (a-e); gain $10^{5}$ (a-e); sweep time, $83.89 \mathrm{~s}$ (a-e); conversion time, $82 \mathrm{~ms}(a-e)$.

As the hydroxyl adduct might be observed after a nucleophilic addition of water on nitrone, solutions of nitrone $\underline{7 c}$ were let $24 \mathrm{~h}$ in $100 \mathrm{mM}$ neutral phosphate buffer and without a supplemental addition of metal traces. After an oxygen bubbling, we did not observed ESR signal of $\underline{\mathbf{7}}-\mathrm{OH}$ adduct. Therefore, the hydroxyl radical adduct observed in the superoxide trapping experiments originated from the superoxide adduct decay. Addition of a high concentration of mannitol (6 time higher than the nitrone concentration) (fig 6c) or of catalase $\left(2600 \mathrm{u} \times \mathrm{mL}^{-1}\right.$, fig $\left.6 \mathrm{~d}\right)$ inhibit the cis hydroxyl adduct formation but did not inhibit the trans hydroxyl adduct (18\% and $23 \%$ after 16 min incubation respectively) indicating that the trans hydroxyl adduct was directly produced from the superoxide adduct. However, formation of the cis hydroxyl adduct in the absence of mannitol proved the production of the hydroxyl radicals in the degradation pathway. Furthermore the hydroxyl adduct appeared faster with increasing $\mathrm{KO}_{2}$ concentration. Slower degradation of the superoxide adduct and slower apparition of the hydroxyl adduct were observed when using $\left(\mathrm{XO} / \mathrm{O}_{2} / \mathrm{HX}\right)$ generating system instead of $\mathrm{KO}_{2}$ system (fig 7b) and the argon bubbling has a supplementary beneficial effect. Therefore the oxidant species such as superoxide and hydrogen peroxide are probably involved in this degradation mechanism. Thus this degradation into the hydroxyl adduct is not spontaneous and should not occur in vivo in a preponderant manner at the biological concentration encountered in oxidant species.

\section{Experimental}

Chemicals

Drying of the solvents was made by distillation under inert atmosphere in the presence of sodium and benzophenone for THF, diethyloxide and toluene, in the presence of magnesium for methanol, ethanol and $\mathrm{P}_{2} \mathrm{O}_{5}$ for dichloromethane. Melting points were taken on a B510 Büchi capillary apparatus and were left uncorrected. ${ }^{31} \mathrm{P} \mathrm{NMR},{ }^{1} \mathrm{H}$ NMR and ${ }^{13} \mathrm{C} \mathrm{NMR}$ spectra were recorded at 121.49, 300.13 and $75.54 \mathrm{MHz}$ respectively, or at $81.01,200.13$ and $50.32 \mathrm{MHz}$ respectively. ${ }^{31} \mathrm{P} \mathrm{NMR}$ was taken in $\mathrm{CDCl}_{3}$ using $85 \% \mathrm{H}_{3} \mathrm{PO}_{4}$ as an external standard with broad-band ${ }^{1} \mathrm{H}$ decoupling. ${ }^{1} \mathrm{H} \mathrm{NMR}$ and ${ }^{13} \mathrm{C}$ NMR were taken in $\mathrm{CDCl}_{3}$ using TMS or $\mathrm{CDCl}_{3}$ as internal reference, respectively. Chemical shifts $(\delta)$ are reported in ppm and coupling constant $J$ values in Hertz. The assignments of NMR signals were facilitated by use of the DEPT 135 sequence for all products. Interpretation of some spectra was achieved by comparing ${ }^{1} \mathrm{H}$ homonuclear correlation (NOESY ${ }^{1} \mathrm{H}_{-}{ }^{1} \mathrm{H}$ ). Positive ion ES mass spectra and tandem mass spectra were acquired in a triple quadripole mass spectrometer equipped with a pneumatically assisted ES source (nebulizing gas, AIR at a $0.8 \mathrm{~L} / \mathrm{min})$.

Ethyl 2-cyano-4-diethoxypentanoate (2). The mixture of ethyl 2-cyano-4-oxopentanoate $\underline{\mathbf{1}}^{12}(10.0 \mathrm{~g}, 59.2 \mathrm{mmol})$ and resin Amberlyst $15(4.5 \mathrm{~g})$ in triethylorthoformate $(45 \mathrm{~mL})$ was stirred for $20 \mathrm{~h}$ at $0-5{ }^{\circ} \mathrm{C}$. After resin filtration and extraction with $\mathrm{CH}_{2} \mathrm{Cl}_{2}(10 \mathrm{~mL})$ the solvent and triethylorthoformate were evaporated under reduced pressure to afford pure ethyl 2cyano-4-diethoxypentanoate $\underline{\mathbf{2}}$ as a green oil (14.2 g, 99\% yield). ${ }^{1} \mathrm{H}$ NMR (100.13 MHz) $\delta 4.26(2 \mathrm{H}, \mathrm{q}, J=7.2), 3.6(1 \mathrm{H}$, $\mathrm{m}), 3.47$ (2H, q, $J=7.0), 3.44(2 \mathrm{H}, \mathrm{q}, J=7.0), 2.2-2.4(2 \mathrm{H}, \mathrm{m})$, 
$1.4(3 \mathrm{H}, \mathrm{s}), 1.33(3 \mathrm{H}, \mathrm{t}, J=7.1), 1.17(3 \mathrm{H}, \mathrm{t}, J=7.1), 1.16(3 \mathrm{H}$, $\mathrm{t}, J=7.1) .{ }^{13} \mathrm{C}$ NMR (40.5 MHz) $\delta 167.1(\mathrm{~s}), 117.9$ (s), 100.2 (s), $63.0(\mathrm{~s}), 56.6(\mathrm{~s}), 56.5$ (s), 37.8 (s), 33.8 (s), 22.4 (s), 15.5 (s), $14.1(\mathrm{~s})$.

2-Aminomethyl-4-diethoxypentanol (3) At a solution of $\mathrm{LiAlH}_{4}(4.3 \mathrm{~g}, 113.1 \mathrm{mmol})$ in THF $(70 \mathrm{~mL})$ was added dropwise at $20-30{ }^{\circ} \mathrm{C}$ a solution of $\underline{\mathbf{2}}(14.9 \mathrm{~g}, 61.3 \mathrm{mmol})$ in THF (130 mL). Then the mixture was stirred for $3 \mathrm{~h}$ at $25^{\circ} \mathrm{C}$ and $1 \mathrm{~h}$ at $57{ }^{\circ} \mathrm{C}$. The reaction mixture was next treated by addition of brine $(100 \mathrm{~mL})$ saturated with $\mathrm{NaCl}$ and extraction with $\mathrm{Et}_{2} \mathrm{O}(3 \times 200 \mathrm{~mL})$. The organic layer was dried over $\mathrm{Na}_{2} \mathrm{SO}_{4}$ and after evaporation of the solvents the residue was distillated under reduced pressure $\left(95-100{ }^{\circ} \mathrm{C} / 0.05 \mathrm{mmHg}\right)$ to give rise to pure 2-aminomethyl-4-diethoxypentanol as a white oil (4.5 g, 36\% yield not optimized). ${ }^{1} \mathrm{H}$ NMR (100.13 MHz) $\delta$ $3.65-3.75(2 \mathrm{H}, \mathrm{m}), 3.51(2 \mathrm{H}, \mathrm{q}, J=7.2), 3.47(2 \mathrm{H}, \mathrm{q}, J=7.2)$, $2.84(1 \mathrm{H}, \mathrm{m}), 2.5-2.6(2 \mathrm{H}, \mathrm{m}), 1.8-1.9(1 \mathrm{H}, \mathrm{m}), 1.55-1.65(2 \mathrm{H}$, $\mathrm{m}), 1.36(3 \mathrm{H}, \mathrm{s}), 1.16(3 \mathrm{H}, \mathrm{t}, J=7.2)$.

Diethyl (4-hydroxymethyl-1-methylpyrrolidin-2-yl) phosphonate (5). The solution of $\underline{\mathbf{3}}(2.9 \mathrm{~g}, 19.02 \mathrm{mmol})$ in $\mathrm{THF} / \mathrm{H}_{2} \mathrm{O}(5: 1,72 \mathrm{~mL})$ was stirred for $3 \mathrm{~h}$ in the presence of $5 \% \mathrm{HCl}$. It was next stirred for $2 \mathrm{~h}$ at $\mathrm{pH} 8$ after addition of $\mathrm{K}_{2} \mathrm{CO}_{3}$. After saturation with $\mathrm{NaCl}$ of the solvents the product was extracted with $\mathrm{Et}_{2} \mathrm{O}(3 \times 25 \mathrm{~mL})$. The organic layer was dried over $\mathrm{Na}_{2} \mathrm{SO}_{4}$ and after evaporation of the solvents, the residue was verified as 4-hydroxymethyl-1-methyl-2-pyrroline 4 through ${ }^{13} \mathrm{C}$ NMR $\left(25.1 \mathrm{MHz}, \mathrm{C}_{6} \mathrm{D}_{6}\right) \delta 175.3,64.3,63.5$, $42.0,39.6,19.3$. This residue was then stirred for 7 days at 25 ${ }^{\circ} \mathrm{C}$ in the presence of diethylphosphite $(2.7 \mathrm{~g}, 19.4 \mathrm{mmol})$. After that, water $(30 \mathrm{~mL})$ was added and the mixture was acidified until $\mathrm{pH}$ 1. The aqueous layer was washed with $\mathrm{CHCl}_{3}(4 \times 15$ $\mathrm{mL})$ then basified with $\mathrm{K}_{2} \mathrm{CO}_{3}$ and extracted with $\mathrm{CHCl}_{3}(4 \times$ $15 \mathrm{~mL}$ ). The resulting organic layer was dried over $\mathrm{Na}_{2} \mathrm{SO}_{4}$ and evaporation of the solvents under reduced pressure lead to a brown oil corresponding to $\underline{\mathbf{5}}\left(1.9 \mathrm{~g}, 40 \%\right.$ yield) in mainly ( $1 \mathrm{R}^{*}$, $\left.4 \mathrm{R}^{*}\right)$ configuration. ${ }^{31} \mathrm{P} \mathrm{NMR}(25.1 \mathrm{MHz}) \delta 29.48(3 \%) ; 29.0$ (97\%); ${ }^{1} \mathrm{H}$ NMR $(100.13 \mathrm{MHz}) \delta 4.15(4 \mathrm{H}$, five lines, $J=7.0$, 7.0), 3.5-3.7 (3H, m), 3.1-3.3 (1H, m), 2.8-3.0 (1H, m), 2.1-2.3 $(4 \mathrm{H}, \mathrm{m}), 1.4(3 \mathrm{H}, \mathrm{d}, J=13.0), 1.32(6 \mathrm{H}, \mathrm{t}, J=7.0) ;{ }^{13} \mathrm{C} \mathrm{NMR}$ $(40.5 \mathrm{MHz}) \delta 65.0(\mathrm{~s}), \quad 62.3(\mathrm{~s}), \quad 62.0(\mathrm{~s}), 59.9\left(\mathrm{C}^{\mathrm{IV}}, \mathrm{d}, J=\right.$ 161.3), 49.5 (d, $J=5.5), 42.1$ (d, $J=3.5), 37.7$ (d, $J=3.2), 24.3$ $(\mathrm{d}, J=6.8), 19.3(\mathrm{~s}), 16.5(\mathrm{~s})$,.

\section{5-Diethoxyphosphoryl-3-hydroxymethyl-5-methyl-1-}

pyrroline $\mathbf{N}$-oxide (ㅁ). Phosphonate $\underline{\mathbf{5}}(1.76 \mathrm{~g}, 6.63 \mathrm{mmol})$ was added to sodium tungstate $(0.097 \mathrm{~g}, 29.4 \mathrm{mmol})$ dissolved in 3 $\mathrm{mL}$ of distilled water and $6 \mathrm{~mL}$ of methanol. To the solution cooled down to $0{ }^{\circ} \mathrm{C}, 30 \% \mathrm{H}_{2} \mathrm{O}_{2}(1.43 \mathrm{~mL}, 0.378 \mathrm{~mol})$ was added dropwise. The pale yellow reaction mixture was stirred at $0{ }^{\circ} \mathrm{C}$ until the colour darkened, then it was stirred at $4{ }^{\circ} \mathrm{C}$ for 48 $\mathrm{h}$. When the reaction was virtually complete the aqueous layer was saturated with $\mathrm{NaCl}$ and the expected nitrone was extracted with $\mathrm{CH}_{2} \mathrm{Cl}_{2}(4 \times 10 \mathrm{~mL})$. The collected organic phase was dried over $\mathrm{Na}_{2} \mathrm{SO}_{4}$ and the solvent was removed under reduced pressure. The crude nitrone was purified with chromatography on silicagel eluting with $\mathrm{CH}_{2} \mathrm{Cl}_{2} / \mathrm{EtOH}(86: 14)$ and this allowed us to collect pyrroline N-oxide $\underline{\mathbf{6}}$ ( $0.6 \mathrm{~g}, 32 \%$ yield) in mainly $\left(3 \mathrm{R}^{*}, 5 \mathrm{R} *\right)$ configuration as a yellow oil. ${ }^{31} \mathrm{P} \mathrm{NMR}(25.1 \mathrm{MHz})$ $\delta 22.15(3 \%) ; 21.8(97 \%) ;{ }^{1} \mathrm{H}$ NMR $(100.13 \mathrm{MHz}) \delta 7.06(1 \mathrm{H}$, $\mathrm{q}, J=2.8,2.8), 4.91(1 \mathrm{H}, \mathrm{s}),, 4.0-4.5(4 \mathrm{H}, \mathrm{m}), 3.2-3.8(3 \mathrm{H}, \mathrm{m})$, 2.6-3.1 (1H, m), 1.8-2.2 (1H, m), $1.7(3 \mathrm{H}, \mathrm{d}, J=15.0), 1.35$ $(6 \mathrm{H}, \mathrm{t}, J=7.0) .{ }^{13} \mathrm{C}$ NMR $(40.5 \mathrm{MHz}) \delta 139.5(\mathrm{~d}, J=8.3), 74.8$ $\left(\mathrm{C}^{\mathrm{IV}}, \mathrm{d}, J=154.2\right), 63.9(\mathrm{~d}, J=6.5), 62.9(\mathrm{~d}, J=7.5), 62.0(\mathrm{~d}, J$ $=4.5), 42.1(\mathrm{~s}), 33.3(\mathrm{~s}), 21.0(\mathrm{~s}), 16.4(\mathrm{~s}), 16.1(\mathrm{~s})$. $\mathrm{C}_{12} \mathrm{H}_{24} \mathrm{NO}_{8} \mathrm{P}$ requires: $\mathrm{C} 45.28$; $\mathrm{H}$ 7.60; N 5.28. Found: $\mathrm{C} 45.0$; H 7.81; N 5.15.

\section{(6-Ethoxy-6a-methyl-5-oxa-6-oxophospholan-6-yl)-1-} pyrroline-N-oxide (MEOOPPO) (ㅇ). To a solution of nitrone 7c ${ }^{9}(0.2 \mathrm{~g}, 0.75 \mathrm{mmol})$ in $\left(4 \mathrm{R}^{*}, 5 \mathrm{R}^{*}\right)$ configuration in dimethoxyethane $(5 \mathrm{~mL})$ was added oily $\mathrm{NaH}(60 \%, 0,017 \mathrm{~g}$, $0.045 \mathrm{mmol}$ ) at $0{ }^{\circ} \mathrm{C}$. The reaction mixture was stirred for $16 \mathrm{~h}$ at room temperature. The precipitate was filtered and washed with $\mathrm{CH}_{2} \mathrm{Cl}_{2}(10 \mathrm{~mL})$. The mixed filtrates were concentrated under reduced pressure to give the crude product. It was purified by flash chromatography on silicagel eluting with $\mathrm{CH}_{2} \mathrm{Cl}_{2} / \mathrm{EtOH}(85: 15)$ to afford the pure nitrone $\underline{\mathbf{8}}$ as a red oil in $45 \%$ yield $(0.075 \mathrm{~g}, 0.34 \mathrm{mmol}) .{ }^{31} \mathrm{P} \mathrm{NMR}(121.49 \mathrm{MHz}) \delta$ 34.07; ${ }^{1} \mathrm{H}$ NMR (300.13 MHz) $\delta 6.81(1 \mathrm{H}, \mathrm{q}, J=2.5), 4.5-4.03$ (4H, m), 3.20-2.90 (2H, m), 2.70-2.53 (1H, m), $1.84(3 \mathrm{H}, \mathrm{d}, J=$ 14.9), $1.35(3 \mathrm{H}, \mathrm{t}, J=7.0) ;{ }^{13} \mathrm{C}$ NMR $(75.47 \mathrm{MHz}) \delta 131.7(\mathrm{~d}, J$ $=7.7), 74.5\left(\mathrm{C}^{\mathrm{IV}}, \mathrm{d}, J=131.1\right), 67.0(\mathrm{~d}, J=8.8), 66.0(\mathrm{~d}, J=$ $7.5), 45.6$ (d, $J=11.0), 31.5$ (s), 19.5 (d, $J=3.3), 16.3$ (d, $J=$ 6.6). ESI-MS/MS $(20 \mathrm{eV}) \mathrm{m} / \mathrm{z}(\%): 220.2(100)[\mathrm{M}+\mathrm{H}]^{+}, 192$ (26), 174 (3), 156 (25), 138 (2), 110 (14), 94.1 (20).

\section{Spin Trapping Studies.}

Xanthine oxidase (XO), bovine erythrocyte superoxide dismutase (SOD) and catalase were purchased from Boehringer Mannheim Biochemical Co.; diethylenetriaminepentaacetic acid (DTPA) and other chemicals were purchased from Sigma Chemical Co. ESR spectra were recorded at room temperature using a Bruker ESP 300 ESR spectrometer at $9.5 \mathrm{GHz}$ (X-band) employing $100 \mathrm{kHz}$ field modulation. Reaction mixtures were prepared in a chelex-treated phosphate buffer $(0.1 \mathrm{M}, \mathrm{pH} 7.3)$.

Superoxide trapping with hypoxanthine-xanthine oxidase generating system. $\mathrm{XO}\left(0.04 \mathrm{U} \mathrm{mL}^{-1}\right)$ was added to a mixture of nitrone (50 to $60 \mathrm{mM})$, DTPA $(1 \mathrm{mM})$, and HX $\left(0.4 \mathrm{U} \mathrm{mL}^{-1}\right)$ in phosphate buffer (0.1 M, pH 7.3). When SOD (606 $\mathrm{U} \mathrm{mL}^{-1}$ ) was added to the HX/XO generating system for an inhibition test of superoxide trapping, it was added before $\mathrm{XO}$ addition.

Superoxide trapping using $\mathrm{KO}_{2} / 18$-crown-6 generating system. ESR signal observed upon incubating the reaction mixture obtained after adding $\mathrm{KO}_{2}$ (10 $\mathrm{mM}$ final concentration) and 18-crown-6 ether (10 mM final concentration) in DMSO to phosphate buffer $(0.1 \mathrm{M}, \mathrm{pH} 7.3)$ containing nitrone (50 to 60 $\mathrm{mM}$ final concentration).

Hydroxyl trapping using Fenton generating system. The hydroxyl radical was generated by addition of $\mathrm{FeSO}_{4}(2 \mathrm{mM})$ to a mixture of nitrone (50 to $60 \mathrm{mM}$ ), DTPA (1 mM), and $\mathrm{H}_{2} \mathrm{O}_{2}$ (2 $\mathrm{mM})$ in phosphate buffer $(0.1 \mathrm{M}, \mathrm{pH} 7.3)$. When catalase 
(600 $\mathrm{U} \mathrm{mL}^{-1}$ ) was added to the incubation mixture for an inhibition test of hydroxyl trapping, it was added before $\mathrm{FeSO}_{4}$ addition.

(HO) $\mathrm{H}_{2} \mathbf{C}^{\bullet}$ Trapping: The carbon centred of $\mathrm{MeOH}$ was generated by the Fenton system in the presence of nitrone (61 $\mathrm{mM})$ and $\mathrm{MeOH}(10 \%)$.

$\mathrm{H}_{3} \mathrm{C}-(\mathrm{OH}) \mathrm{HC}^{\bullet}$ Trapping. The carbon centred of EtOH was generated by the Fenton system in the presence of nitrone (61 $\mathrm{mM})$ and $\mathrm{EtOH}(10 \%)$.

HOOC $^{\bullet}$ Trapping. The carbon centred of $\mathrm{HCOOH}$ was generated by the Fenton system in the presence of nitrone (61 $\mathrm{mM})$ and $\mathrm{HCOOH}(10 \%)$.

Methyl Trapping. The methyl radical adduct was generated by Fenton System in the presence of nitrone $(61 \mathrm{mM})$ and DMSO (5\%) under argon atmosphere.

\section{Conclusion}

In the series of pyrroline $N$-oxide with a phosphonate group, the dynamic process between two rotamers of superoxide or peroxyl adducts appeared difficult to avoid. Between the hydroxymethyl substituted analogues of DEPMPO, the cis isomer $\mathrm{C}_{4}$ substituted 4-HMcDEPMPO is the only one to trapped superoxide and peroxyl radicals in a stereoselective manner. The presence of a hydroxylmethyl group on the $\mathrm{C}_{4}$ of the pyrroline ring in the cis position favors addition of the superoxide radical on the face opposite to the phosphoryl group. The ESR signal of the superoxide or peroxyl adduct of 4-HMcDEPMPO were more easily assignable than for DEPMPO: the alternating line-width phenomenon due to the chemical exchange between the conformer sets is existing $(0.1$ $\mathrm{mT}$ up to $0.25 \mathrm{mT}$ ) but less visible. In comparison with DEPMPO $\left(\mathrm{k}=15,7 \times 10^{7}\right.$ for DEPMPO-OOH, ${ }^{14} \mathrm{k}=0.9 \times 10^{7}$ at $223 \mathrm{k}$ for DEPMPO-OO' $\left.{ }^{t} \mathrm{Bu}\right)$, the presence of a hydroxylmethyl group on the $\mathrm{C}_{4}$ of the pyrroline ring on the face of the phosphoryl group slows down the pseudo-rotation of the rotamers of the trans superoxide adduct ( 9 fold smaller exchange rate) and slightly that of the trans terbutylperoxyladduct. ( 2 fold smaller exchange rate at $223^{\circ} \mathrm{K}$ ). The conformational exchange broadening slightly the lines of the signal did not impede the reading of the corresponding spectra. The shapes of the signals of the 4-HMcDEPMPO-OOHt and 4HMcDEPMPO-OORt adduct are strongly characteristic of the species added and can be easily recognized in spectra with superimposed signals of adducts of various kinds of radicals. For conformers of both superoxide adduct and methylperoxyl radical adduct, the pseudo-axial $\mathrm{C}-\mathrm{OOH}$ bond (and also the $\mathrm{C}-\mathrm{P}$ bond for the major conformer) can stabilize the nitroxide moiety by anomeric effects. Moreover this axial position of the $\mathrm{C}-\mathrm{P}$ bond of the 4HMcDEPMPO-OOHt can explain its persistency $25 \%$ higher than the one of DEPMPO-OOH. Despite $\mathrm{C}_{4}$ substitution does not limit the dismutation of the nitroxide, as a possible alternative reaction path, the major decay mechanisms observed in our buffer experiment involved some concentration of oxidant that can be modulate. Therefore, this nitrone appeared as a very good tool for superoxide or peroxyl radicals detection. The substitution on the $\mathrm{C}_{4}$ of the pyrroline ring on the opposite face to the phosphoryl group slows down the pseudo-rotation of the rotamers of the trans superoxide adduct (25 fold smaller exchange rate) but the spectra are more complex because of a non stereoselective addition of superoxide and a weaker persistency of the adduct. When the conformation of the ring substituted in $\mathrm{C}_{4}$ position was blocked by a second cycle involving phosphonate, the bicycle formed was too much constrained and did not afford a superoxide adduct particularly persistent because of a pseudoequatorial orientation of the $\mathrm{C}-\mathrm{P}$ bond. In comparison with DEPMPO the presence of a hydroxylmethyl group on the $\mathrm{C}_{3}$ of the pyrroline ring on the face opposite to the phosphoryl group slows down the pseudo-rotation of the rotamers of the trans superoxide adduct (12 fold smaller exchange rate) and particularly of the trans terbutylperoxyl-adduct. (18 fold smaller exchange rate at $223^{\circ} \mathrm{K}$ ) but it does not impede it wholly. Moreover in these substitution case, superoxide and peroxyl diastereoisomer adducts were obtained; their superimposed ESR signals afforded complex spectra. Every nitrone studied presented two diastereoisomer adducts with hydroxyl radical, although, the cis addition with the cis isomer $\mathrm{C}_{4}$-substituted 4-HMcDEPMPO was also disfavored. With carbon centred radicals diastereoisomer adducts were also generally obtained, exept for nitrone 4HMcDEPMPO.

\section{Acknowledgements}

A. R. thanks the Hungarian Science Fund for partial funding of this work (grant OTKA T-046953).

\section{Notes and references}

1 B. Halliwell, Am. J. Med., 1991, 91, 3C, 14S; B. Halliwell and J. M. C. Gutteridge, Am. J. Med., 1984, 219, 1; B. Halliwell and S. Chirico, Am. J. Clin. Nutr., 1993, 57(S), 715S.

2 a) E. Finkelstein, G. M. Rosen and E. J. Rauckman, J. Am. Chem. Soc., 1980, 102, 4994. b) A Samuni, C. Murali Krishna, P. Riesz, E. Finkelstein and A. Russo, Free Radicals Biol. Med, 1989, 6, 141. c) G. R. Buettner, Free Rad. Res. Comms., 1990, 10, 11.

3 a) C. Frejaville, H. Karoui, B. Tuccio, F. Le Moigne, M. Culcasi, S. Pietri, R. Lauricella and P. Tordo, J. Med. Chem., 1995, 38, 258. b) S. Barbati, J. L. Clément, G. Olive, V. Roubaud, B. Tuccio and P. Tordo, Free Radicals in Biology; Environment, Ed. F. Minisci, NATO ASI Series, Life Sciences, Kluwer Academic Publishers : Dordrecht (Netherl;s), 1997, chapter 3, 39.

4 H. Karoui, F. Chalier, J.- P. Finet and P. Tordo, Org. Biomol. Chem., 2011, 9, 2473.

5 J. C. Matasyoh, P. Schuler, H. B. Stegmann, J. L. Poyer, M. West and E. G. Janzen, Magn. Res. Chem., 1996, 34, 351-359.

6 L. Dembkowski, J.-P. Finet, C. Frejaville, F. Le Moigne, R. Maurin, A. Mercier, P. Pages, P. -L. Stipa and P. Tordo, Free Rad. Res. Com., 
1993, 19, S23. C. Chachaty, C. Mathieu, A. Mercier and P. Tordo, Magn. Res. Chem., 1998, 36, 46.

7 C. Nsanzumuhire, J.-L. Clément, O. Ouari, H. Karoui, J.-P. Finet and P. Tordo, Tetrahedron Lett., 2004, 45, 6385.

8 M. Hardy, F. Chalier, J.-P. Finet, A. Rockenbauer and P. Tordo, J .Org. Chem., 2005, 70, 2135

9 F. Chalier.; M. Hardy, J.-P. Finet, O. Ouari, A. Rockenbauer and P. Tordo, J.Org. Chem., 2007, 72, 7888.

10 a) J. W. Davies, J. R Malpass and M. P. J. Walker, Chem. Soc. Comm., 1985, 686. b) M.Pirrung, Tetrahedron Lett., 1980, 21, 4577. c) P. Hughes, M. Martin and J. Clardy, Tetrahedron Lett. 1980, 21, 4579.

11 a) J. Davoll, J. Chem. Soc. 1960, 131. b) F. Seela and U. Lüpke, Chem. Ber. 1977, 110, 1462.

12 A. Y. Sizov, L. A. Yanovskaya, V. Dombrovskii and A. Baccat Bull. Acad. SCI. USSR, div. Chem. Sci. (Engl. Transl) EN 1990, 39, 2.2, 410 (Izv. Akad. Nauk, SSSR Ser. Khim. 1990, 473.

13 A. Rockenbauer and L Korecz,. Appl. Magn. Reson. 1996, 10, 29-43.

14 A. Rockenbauer, J.-L. Clément, M. Culcasi, A. Mercier, P. Tordo and S. Pietri, J. Phys. Chem. A , 2007, 111, 4950.

15 D. Cremer and J. Pople, J. Am. Cem. Soc., 1975, 97, 1354. Ibid, 1358.

16 A. Rockenbauer, L Korecz and K. Hideg, J. Chem. Soc., Perkin Trans. 2., 1993, 11, 2149. A. Rockenbauer, M. Györ, H. O. Hankovsky and K. Hideg, ESR study of the conformation of 5- and 6membered cyclic nitroxides (aminoxyl) radicals. In Electron Spin Resonance; Symons, M. C. R., Ed.; Royal Society of Chemistry: Cambridge, UK, 1988; 11A, 145.

17 It was sometimes named $\left\langle{ }^{3} \mathrm{E}-\mathrm{E}_{4}\right\rangle$ geometry in others papers such as ref. 14.

18 J.-L. Clément, N. Ferré, D. Siri, H. Karoui, A. Rockenbauer and P. Tordo, J. Org.Chem., 2005, 70, 1198.

19 C. Houriez, N. Ferré, D. Siri, P. Tordo, and M. Masella J. Chem. Phys., 2010, 114, 11793.

20 C. Houriez, N. Ferré, D. Siri, P. Tordo, and M. Masella J Theor. Chem. Acc., 2012, 131, 1.

21 For a detailed explanation of this simulation method, used also to study the superoxide adduct of DEPMPO, see ref. 14

22 The trans-adduct DEPMPO-OO ${ }^{t} \mathrm{Bu}$ adduct $\mathrm{T}_{1}$ has the parameters: $\mathrm{A}_{\mathrm{N}}$ $=1.234 \mathrm{mT}, \mathrm{A}_{\mathrm{P}}=5.280 \mathrm{mT}, \mathrm{a}_{\mathrm{H} \beta}=1.103 \mathrm{mT}$ and $\mathrm{T}_{2}: \mathrm{A}_{\mathrm{N}}=1.234 \mathrm{mT}$ , $\mathrm{A}_{\mathrm{P}}=4.798 \mathrm{mT}, \mathrm{A}_{\mathrm{H} \beta}=0.768 \mathrm{mT}$ with $\mathrm{k}=0.9 \times 10^{7}$ at $223 \mathrm{k}$. The cis DEPMPO-OO ${ }^{t} \mathrm{Bu}$ adduct was also involved in the spectra signals and the ESR parameters of its two conformers were found to be at $223 \mathrm{k}$ : for $\mathrm{T}_{1}, \mathrm{~A}_{\mathrm{N}}=1.333 \mathrm{mT}, \mathrm{A}_{\mathrm{P}}=4.075 \mathrm{mT}, \mathrm{A}_{\mathrm{H} \beta}=0.930 \mathrm{mT}$ and for $\mathrm{T}_{2}$ : $\mathrm{A}_{\mathrm{N}}=1.338 \mathrm{mT}, \mathrm{A}_{\mathrm{P}}=3.478 \mathrm{mT}, \mathrm{A}_{\mathrm{H} \beta}=0.850 \mathrm{mT}$ with $\mathrm{k}=2.3 \times 10^{7}$. 